Florida International University FIU Digital Commons

4-21-1999

\title{
The effects of participation in an arthritis foundation sponsored aquacize program on health status
}

Rose Ann Ruggiero Curboy

Florida International University

DOI: $10.25148 /$ etd.FI14061571

Follow this and additional works at: https://digitalcommons.fiu.edu/etd

Part of the Occupational Therapy Commons

\section{Recommended Citation}

Curboy, Rose Ann Ruggiero, "The effects of participation in an arthritis foundation sponsored aquacize program on health status" (1999). FIU Electronic Theses and Dissertations. 2695.

https://digitalcommons.fiu.edu/etd/2695 


\section{FLORIDA INTERNATIONAL UNIVERSITY \\ Miami, Florida}

\section{THE EFFECTS OF PARTICIPATION IN AN ARTHRITIS FOUNDATION SPONSORED AQUACIZE PROGRAM ON HEALTH STATUS}

A thesis submitted in partial fulfillment of the

requirements for the degree of

MASTER OF SCIENCE

in

OCCUPATIONAL THERAPY

by

Rose Ann Ruggiero Curboy 
To: Dean DeLois P. Weekes

College of Health Sciences

This thesis, written by Rose Ann Ruggiero Curboy, and entitled THE EFFECTS OF PARTICIPATION IN AN ARTHRITIS FOUNDATION SPONSORED AQUACIZE PROGRAM ON HEALTH STATUS, having been approved in respect to style and intellectual content, is referred to you for your judgment.

We have read this thesis and recommend that it be approved.

\author{
Alma Abdel-Moty \\ Paulette Johnson
}

Susan Kaplan, Major Professor

Date of Defense: April 21, 1999

The thesis of Rose Ann Ruggiero Curboy is approved.

Dean DeLois P. Weekes

College of Health Sciences

Dean Richard L. Campoeıl

Division of Graduate Studies

Florida International University, 1999 


\section{DEDICATION}

I dedicate this thesis to my late parents. Unfortunately they were not able to see me realize my goals, but I know they would have been proud. They always encouraged me to learn and grow and be the best I could be.

Many thanks to my family and friends who continued to support and encourage me and understood my neglect during these past few years.

I would like to thank Kathy Andio for allowing me to use her Arthritis Foundation aquacize class for my study, for her enthusiastic recruitment of new participants, for her assistance with keeping track of their participation, for collecting questionnaires, and especially for her support during this long process.

Most of all, I would like to thank my husband, Ron, who without all of his help the completion of this thesis would not have been possible. He encouraged me to follow my dreams, to quit my job and return to school despite the hardships of having to be apart throughout the week. He supported me throughout the long process of completing this thesis and all the personal difficulties that intervened. His love and support kept me going. 


\section{ACKNOWLEDGMENTS}

I would like to thank the members of my committee, Susan Kaplan, Ph.D., Alma Abdel-Moty, M.S., and Paulette Johnson, Ph.D. for all of their assistance, comments, phone calls and email messages, and especially for their patience during this long process.

Dr. Johnson, you definitely earned your salary with all your hours of statistical help, the tedious programming of the AIMS2 questionnaire, and helping me to interprete the masses of data. You definitely do too much, and I appreciate it.

Alma, thank you for your continued support and encouragement throughout.

A special thanks must go to my major professor, Dr. Susan Kaplan, for understanding when personal situations forced delays, for special arrangements to avoid a long drive, and especially for your confidence in me that I would eventually finish. 
ABSTRACT OF THE THESIS

\title{
THE EFFECTS OF PARTICIPATION IN AN ARTHRITIS FOUNDATION
}

\section{SPONSORED AQUACIZE PROGRAM ON HEALTH STATUS}

\author{
by \\ Rose Ann Ruggiero Curboy \\ Florida International University, 1999 \\ Miami, Florida \\ Professor Susan Kaplan, Major Professor
}

The current study assessed the effects of participation in an Arthritis Foundation sponsored water exercise program on self-reported functioning and health status. Nine older community living women with various forms of arthritis took part in this pre to post-test design study, along with a comparison group of eleven older women also regularly engaged in differing forms of exercise. Both groups completed a standardized questionnaire, the Arthritis Impact Measurement Scales 2, twice over an eight week period. Twelve scales and additional questions measured physical, social, and psychological aspects of daily functioning. Aquacize participants reported significant improvements in the Physical Component area of functioning from pre to post-test, as well as more improvements in Arm Function and Household Tasks than the comparisons. Occupational therapists need to be aware of the efficacy of programs to which they refer their arthritic clients. Findings support regular participation in aquacize has a positive influence on health. 
CHAPTER

PAGE

I. INTRODUCTION

Statement of the Problem...................................................................... 2

Research Hypotheses........................................................................ 5

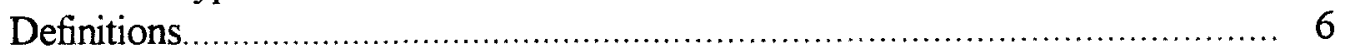

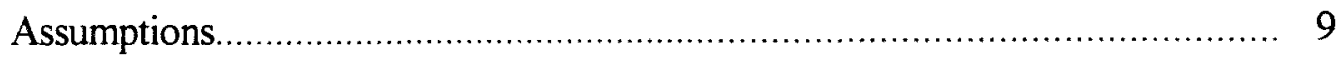

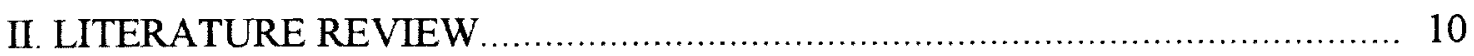

Health and Health Status Instruments................................................ 10

Occupational Therapy Theory and Health............................................. 19

Therapeutic Exercise for Arthritis........................................................ 21

Arthritis Foundation Aquacize Studies................................................. 24

Physical and Psychosocial Effects of Aquacize............................................ 26

Summary of Literature Review........................................................... 43

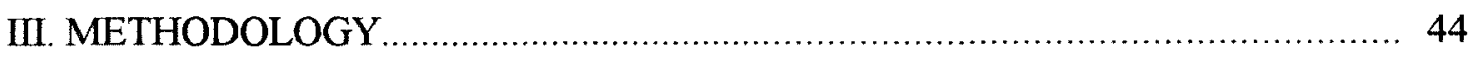

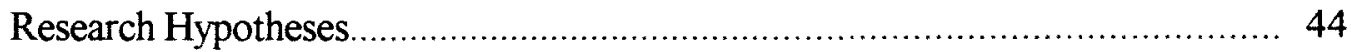

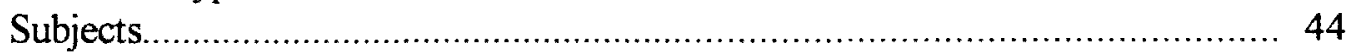

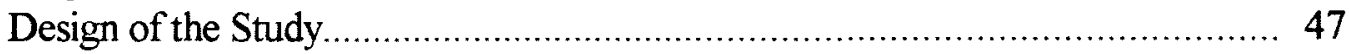

Data Collection Methods ...................................................................... 48

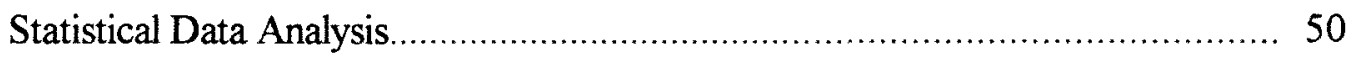

Limitations of the Study..................................................................... 52

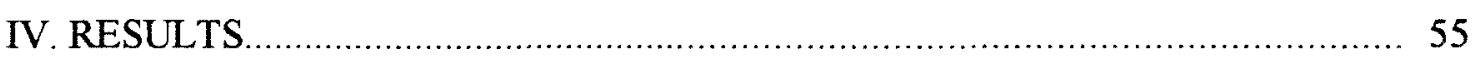

Characteristics of Participants ................................................................ 55

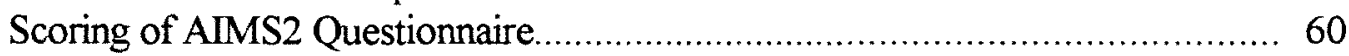

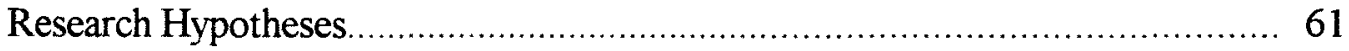

Summary of Results................................................................................... 81

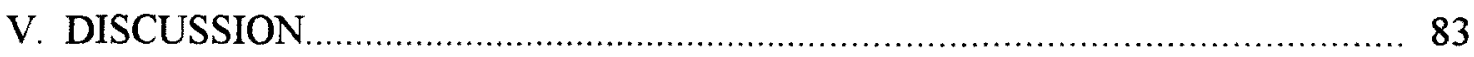

Relationship to Conceptual Framework ................................................... 83

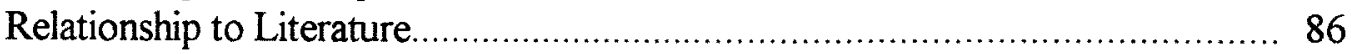

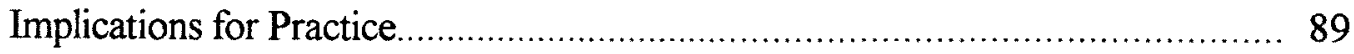

Recommendations for Future Research.................................................. 90

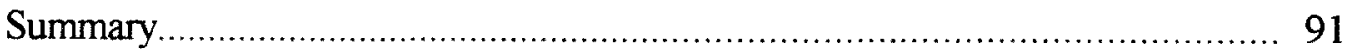

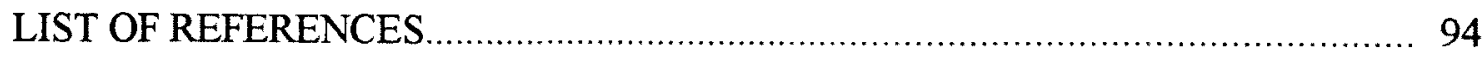

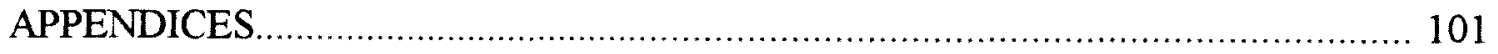




\section{CHAPTER I}

\section{Introduction}

Musculoskeletal and connective tissue disorders are major worldwide causes of chronic pain, severe physical dysfunction, work disabilities, income losses, and numerous psychosocial problems (Berkow \& Fletcher, 1992; Mason, Weener, Gertman, \& Meenan, 1983). The Arthritis Foundation (AF) has reported that nearly 40 million Americans, or one in seven persons, have some form of arthritis (1996c). In 1993, arthritis was the most frequently occurring condition reported in persons over the age of 65 , affecting $49 \%$ of elderly persons (Fowles, 1995). National estimates of the current incidence of osteoarthritis, a disorder commonly afflicting older persons, reach 15.8 million (AF, 1996c).

Arthritis impacts our economy with an estimated \$54 billion annually in medical care and indirect costs such as lost wages (AF, 1996c). Arthritis is the number one cause of disability in our nation (AF, 1996c), limiting the daily life of approximately seven million Americans (AF, 1996c). The Centers for Disease Control and Prevention project that the prevalence of arthritis will increase to 59.4 million Americans by the year 2020 (as cited by the AF, 1996c) when the population of those over 65 is expected to double from current estimates (Fowles, 1995). The envisioned effect of arthritis on future health care systems and the economy in the United States can be devastating.

The Arthritis Foundation is a national, voluntary health organization that offers numerous programs and services to assist persons to manage their arthritis. Their mission "is to support research to find the cure for prevention of arthritis and to improve the quality of life for those affected by arthritis" (AF, 1996b, p. 1). Support groups, self-help classes, educational meetings and materials, videos, and land and water exercise programs are some 
of the offered services. The Arthritis Foundation Aquatic Program (AFAP), is an organized community-based aquacize program co-developed with the Young Men's Christian Association (YMCA) in 1984. A specific protocol of gentle warm water activities is recommended, designed specifically for persons with various forms of arthritis (AF, 1996c).

Water-based exercise programs have shown great gains in popularity with the general public in the past 10 years. In 1986, a half million Americans were found to be regularly involved with "vertical" aquatic exercise (excludes lap swimmers) as a recreational or therapeutic activity. That number had grown to over six million by 1992 (Huey \& Forster, 1993). Aquatic activities are gentle enough on the body to often be accomplished throughout the lifespan. "Adults over the age of 65 are the fastest growing segment of the U.S. population, and the fastest growing category of pool users" (Reister \& Cole, 1993, p.52). Much of this increase is due to the Arthritis Foundation's advocacy of aquatic exercise. More research is needed to validate aquatic exercise as an effective treatment with clinical usefulness for this population.

\section{Statement of the Problem}

The uniform criteria for classification of persons with rheumatoid arthritis (RA) include four classes of functional capacity (Hochberg et al., 1991; Steinbrocker, Traeger, \& Batterman, 1949). The American College of Rheumatology published these classes (Hochberg et al., 1991) as criteria for functional status in RA in order to differentiate the levels of ability to perform usual activities of daily living (self-care, vocational, and avocational). Function can be improved without altering the activity of the disease. Functional impairment is not always proportionate to the amount of structural damage, as evidenced by observable "hard signs" such as roentgenologic evidence, erythrocyte sedimentation rate, and measurements of joint 
effusion, muscle strength, and joint range of motion. Functional impairment often responds to therapeutic intervention (Steinbrocker, Traeger, \& Batterman, 1949).

Arthritic treatment methods that can effectively break the debilitating spiral of pain, inactivity, decreased range of motion, reduced functioning, weakening of the muscles that stabilize joints, and additional pain need to be determined. Preservation and restoration of function are major goals of health professionals' interventions. Due to the chronic and frequently progressive nature of arthritic disorders, rehabilitation interventions may be periodically required after onset to maintain function (Hittle, Pedretti, \& Kasch, 1996; Melvin, 1989).

The causes of functional decline in older persons with arthritis, subsequent restrictions in activity, and inevitable reduction in quality of life are similar to multiple strands woven into a fabric, intertwined, and difficult to separate out. A complex interaction of physiological, psychosocial, and environmental factors determine overall health perceptions and functional abilities (Kielhofner, 1983; Liang \& Jette, 1981; Meenan, Mason, Anderson, Guccione, \& Kazis, 1992).

The concepts of health and function are interwoven as well. The Constitution of the World Health Organization (WHO), adopted in 1946, globally defined health as "a state of complete physical, mental and social well being and not merely the absence of disease and infirmity" (WHO, 1958, p. 459). This model of health formulates the conceptual background of this research study.

Health status and occupation and function are intimately linked concepts underlying the theory and practice of occupational therapy. Health is conceptualized to be maintained through continuation in activity (Rogers, 1989). Activity theory also describes the relationship 
between physical and mental health, life satisfaction, and activity level (Bonder, 1994). Reed and Sanderson (1992) expressed these underlying assumptions regarding a human being: a person is a biopsychosocial and spiritual being, a unified whole that interacts in the environment as a total being; that through performance of occupations a person adapts to or adjusts the environment. The philosophical underpinnings of occupational therapy (Resolution $532-79,1979)$ rest on the premise that persons can influence the state of their health through participation in purposeful activity (occupation).

This researcher hypothesizes that through participation in Arthritis Foundation sponsored aquacize activities, persons with arthritis can influence the state of their health. Inclusion of this occupation into their daily life is hypothesized to be therapeutic in maintaining or improving self-reported functioning and health status, as measured by the twelve scales of the Arthritis Impact Measurement Scales2 (AIMS2).

Occupational therapists are concerned with interventions that maximize the level of physical, social, and psychological well-being of their arthritic clients. Depending on the setting, occupational therapists have differing roles in effecting therapeutic exercise programs (Arthritis Health Professions Association Task Force, 1986). The Arthritis Foundation literature states that their aquacize programs are not intended to be a substitute for individualized therapeutic exercise regimens as prescribed by a health care professional (AF, 1996a; AFAP, 1990). These programs are offered as a complement to clinical treatment (Stenstrom et al., 1991).

Aquatic therapy has been generally accepted by various health professionals to have therapeutic benefits, but occupational therapists have been slow to incorporate this modality into clinical practice. A 1995 survey of 250 randomly selected therapists with a specialty in 
physical disabilities assessed current use of aquatic therapy. Fifty-five percent of the surveyed occupational therapists responded, and of these only 13 percent utilized pool-based activities in their clinical practice (Fricke, 1995).

Occupational therapists that are not directly involved in aquatic therapy frequently refer their arthritic clients to community-based aquacize programs, concurrent with or upon discharge from treatment. Knowledge of the efficacy of available programs can assist occupational therapists in their discharge planning. The Arthritis Foundation advocates aquacize as a method to improve the quality of life of persons afflicted with arthritis, however, empirical studies are essential to ascertain the efficacy of this program. Evaluation of the effects of interventions is a method of quantifying functional ability (Liang \& Jette, 1981). Therefore, ongoing empirical research is necessary to determine if participation in Arthritis Foundation sponsored aquacize programs has an impact on overall health and functioning and the ability to reduce or prevent functional decline in persons with arthritis.

\section{Research Hypotheses}

The purpose of this research is to determine if participation in Arthritis Foundation sponsored water exercise classes can influence health status in older community living persons with various forms of arthritis.

The following research hypotheses have been proposed:

1. Regular participation in Arthritis Foundation sponsored aquacize classes will be effective in improving health status of older persons with arthritis.

2. Older persons with arthritis, after regular participation in Arthritis Foundation sponsored aquacize classes, will report more improvements in health status than a comparison group also regularly engaged in various types of rote or therapeutic exercise. 


\section{Definitions}

Anxiety: An outcome measure of psychological status; a domain of functional health as measured by the AIMS2 (Meenan et al., 1992).

Aquacize: Sometimes called the Arthritis Foundation Aquatic Program (AFAP). Consists of a specific protocol of gentle water activities offered in group sessions by trained and certified instructors. This community-based aquatic exercise program is sponsored by most local chapters of the Arthritis Foundation (AF, 1996a).

Arm function: An outcome measure of elbow and shoulder motion; a domain of functional health as measured by the AIMS2 (Meenan et al., 1992).

Arthritis: Inflammation of one or more joints. There are over 100 arthritic disorders including: osteoarthritis, fibromyalgia, rheumatoid arthritis, gout, ankylosing spondylitis, juvenile rheumatoid arthritis, psoriatic arthritis, and lupus erythematosus. Arthritis is usually a long term condition accompanied by pain, swelling, and changes in structure (Berkow \& Fletcher, 1992; Thomas, 1993).

Functional health: An individual's self-reported ability to perform activities of daily living, and participate in work and leisure activities (Liang \& Jette, 1981; Meenan et al., 1992)

Functional impairment: An individual's inability to perform activities of daily living, and participate in work and leisure activities, as defined by the original (Steinbrocker, Traeger, \& Batterman, 1949) and revised (Hochberg et al., 1991) criteria for functional status in RA (four classes) from the American College of Rheumatology.

Hand and finger function: An outcome measure of dexterity and upper extremity 
physical function; a domain of functional health as measured by the AIMS2 (Meenan et al., 1992).

Health status: A multidimensional outcome measure of physical, emotional and social well-being as measured by the AIMS2 (Meenan et al., 1992).

Household tasks: An outcome measure of routine household activities such as shopping, cooking, housework, laundry; a domain of functional health as measured by the AIMS2 (Meenan et al., 1992).

Level of tension: An outcome measure of psychological status; a domain of functional health as measured by the AIMS2 (Meenan et al., 1992).

Mobility level: An outcome measure of the ability of an individual to move around in the environment; a domain of functional health as measured by the AIMS2 (Meenan et al., 1992).

Mood: An outcome measure of psychological status; a domain of functional health as measured by the AIMS2 (Meenan et al., 1992).

Occupational performance: Accomplishment of specific skills used in work, leisure, self-care, and rest/relaxation (Christensen \& Baum, 1991).

Older persons: Community living individuals age 55 and older.

Osteoarthritis: A degenerative joint disease which is primarily a disorder of hyaline cartilage and subchondral bone, and includes hypertrophy of tissues in and around involved joints (Berkow \& Fletcher, 1992).

Paim: An outcome measure of the frequency and severity of arthritis related pain, morning stiffness, and sleep disturbance; a domain of functional health as measured by the AIMS2 (Meenan et al., 1992). 
Regular participation: Subject's attendance at a minimum of 12 out of 16 consecutive aquacize sessions; and engagement in the activities of the class a minimum of 45 minutes out of a 60 minute session.

Rheumatoid arthritis: "A chronic syndrome characterized by nonspecific, usually symmetric inflammation of the peripheral joints, potentially resulting in progressive destruction of articular and periarticular structures; generalized manifestations may also be present" (Berkow \& Fletcher, 1992, p. 1305).

Self care tasks: An outcome measure of bathing, dressing, toileting, and transferring; a domain of functional health as measured by the AIMS2 (Meenan et al., 1992).

Social activity: An outcome measure of interaction with friends, family, and community; a domain of functional health as measured by the AIMS2 (Meenan et al., 1992).

Support from family and friends: An outcome measure of the qualitative aspect of social interactions; a domain of functional health as measured by the AIMS2 (Meenan et al., 1992).

Therapeutic exercise: Activities that are perceived as meaningful and purposeful to the individual. They provide a naturalistic context for motivating and supporting healthy movement. Task-related social interactions are frequent side benefits (Nelson \& Peterson, 1989).

Walking and bending: An outcome measure of lower extremity physical function; a domain of functional health as measured by the AIMS2 (Meenan et al., 1992).

Work: An outcome measure of role performance and quantity and quality of work; a domain of functional health as measured by the AIMS2 (Meenan et al., 1992). 


\section{Assumptions}

For the purpose of this study, the following assumptions will be made:

1. The sample of community living older persons with various forms of arthritis in this study is representative of the population.

2. The subjects involved in this study will perform to the best of their ability and honestly answer the self-report questionnaire.

3. Exercise is an appropriate activity for persons with various forms of arthritis, in which participation will not be detrimental to their health.

4. A commitment to exercise is important for this population in order to maintain function.

5. The Arthritis Impact Measurement Scales 2 (AIMS2) is a reliable and valid assessment instrument for use in measuring health status in older persons with various forms of arthritis.

6. The AIMS2 is correctly scored and interpreted by the test administrator. 


\section{CHAPTER II}

Review of the Literature

\section{Definition of Health}

In 1946, the World Health Organization (WHO) globally defined health as "a state of complete physical, mental, and social well being, and not merely the absence of disease and infirmity" (WHO, 1958, p. 459). Numerous researchers have attempted to operationalize this broad, abstract definition into a more utilizable conceptualization. Various forms of health status instruments have been developed in the last two decades to address this need. This process has reflected a societal shift of focus from a reductionistic medical model to a more holistic approach to health that incorporates these physical, social, and psychological determinants of well-being (Edwards, 1994; McDowell \& Newell, 1987; Pelletier, 1979).

\section{Health Status Instruments}

Generic health indicators examine the total health of a population, functioning within an epidemiological framework to describe mortality rates, morbidity statistics, incidence of disease, and prevalence reduction in groups (Jette, 1980; Last, 1987; McDowell \& Newell, 1987). Morbidity statistics reveal facets of health; they provide information regarding frequency of symptoms, complaints, impairments, and disabilities (Last, 1987). Health status indicators function to provide a more precise definition of health while focusing on specific aspects of morbidity. They are sensitive measures developed to detect short-term fluctuations in health, particularly in small populations (Last, 1987; Meenan, 1982). Most health status measures are designed to measure the effectiveness of health care interventions (Jette \& Downing, 1994) by both clinicians and researchers. Health status indicators assess multidimensional aspects of health; indices of physical health are combined with measures of social 
and psychological well-being. Their value lies in assessment of patient outcomes as a result of intervention (Last, 1987; Reynolds, 1995).

\section{Self-Report Measures}

Health status instruments employ interviews or self-report questionnaires to measure subjective health judgments in three main categories: well-being, symptoms, and function (McDowell \& Newell, 1987; Reynolds, 1995). Numerous advantages are ascribed to selfreport measures: they are easier to obtain; more convenient than personal interviews; require minimal resources; and the time or assistance of professional staff are not needed, therefore are less costly (McGinnis, Seward, DeJong, \& Osberg, 1986). Self-report measures are capable of detecting both short- and long-term changes in health status (Blalock, 1992). Insight into matters of human concern, quality of experience, and the positive aspects of health are addressed by the obtained "soft" data (McDowell \& Newell, 1987; Reynolds, 1995).

The field of psychophysics provides justification for use of subjective measures of health perception as a valid approach. A domain of concern in psychophysics is the manner in which people perceive and make judgments about physical phenomena, such as the loudness of a sound, or the intensity of a pain. Psychometrics, which incorporates psychophysical principles, provides the techniques used to assign numerical scores to subjective judgments. Psychophysics theorizes mathematical relationships between the intensity of a stimulus and its perception. Fechner's (1860) "just noticeable differences" method of scaling sensations using natural logarithms was supplanted by the power law as proposed by Stevens in 1962. Based on cross-modality matching experiments conducted to validate the power law, psychologists have stated that people can make subjective judgments 
in an internally consistent manner. These principles have been applied to subjective health status indicators; for example, the linear exponential relationship between stimulus and response explains a person's interpretation of a pain visual analogue scale (McDowell \& Newell, 1987).

However, various studies have shown that significant differences exist between patients' self-reports of performance in functional activities and professional evaluation of these patients (Abdel-Moty, Maguire, Kaplan, \& Johnson, 1996; McGinnis, Seward, DeJong, \& Osberg, 1986). Therapists consistently rated patients higher than the patients rated themselves on activities of daily living scales (McGinnis et al., 1986). One explanation for this finding was differing perspectives; therapists tend to emphasize improvements while patients dwell on their previous functional status. Differences are also found between what patients report as their functional level, and what they can actually do. When healthy subjects' and chronic low back pain patients' self-report of their levels of function in squatting and stair climbing were compared with their measured performance in these activities, it was found that both groups underestimated their physical capabilities (Abdel-Moty et al., 1996). The authors concluded that self-reported measures of functional ability should not be used in isolation in clinical evaluations.

\section{Arthritis Impact Measurement Scales}

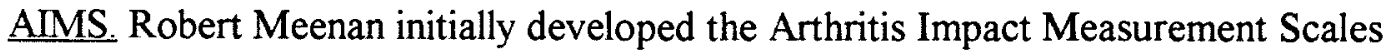
(AIMS) in 1978 to assess the impact of education and community projects on patient outcomes (Meenan, 1982). This researcher felt that other measures of disease activity or functional abilities did not fully address the scope of the broad WHO biopsychosocial conceptualization of health. Other measures focused on physical health to the exclusion of the 
other components (Meenan, Gertman, \& Mason, 1980). Arthritis frequently produces limitations in function in multiple areas; therefore a multi-dimensional approach to outcome measurement was needed (Meenan, Gertman, \& Mason, 1980). The Index of Well Being, developed by Patrick, Bush, and Chen (1973), as well as the battery of measures used in the longitudinal Rand Health Insurance Study (Brook et al., 1979) were modified to create an arthritis-specific self-report instrument (Meenan, 1982; Meenan, Gertman, \& Mason, 1980).

The AIMS consists of a battery of nine scales designed to assess specific aspects of health status: Mobility, Physical Activity, Dexterity, Household Activities, Activities of Daily Living, Social Activity, Anxiety, Depression, and Pain. In addition to these nine scales, four additional general health questions, four health perception questions, three comorbidity items, and eight demographic inquiries are included. Approximate completion time for the selfadministered instrument is 20 minutes (Meenan, 1982).

Numerous investigations to document the reliability, validity, generalizability, and sensitivity of the AIMS were conducted over a three year period. An overall sample of 625 English-speaking persons with various rheumatic diseases undergoing standard care from 15 different clinical settings in 10 different states were used. The majority of subjects $(n=336)$ had rheumatoid arthritis (RA); 108, osteoarthritis (OA); 57, systemic lupus erythematosus (SLE). A Guttman-format scale, constructed for each set of questionnaire items, revealed a range of coefficients of reliability greater than $0.90(p<0.05)$ for the nine scales. Values of 0.90 and or greater are considered an acceptable level of reliability. These scores were converted to Likert coefficients (Cronbach's alpha $>0.70$, a generally accepted level), which could be used to estimate parametric (Pearson) correlation coefficients $(r>0.80)$. The mean test-retest reliability correlation coefficient for the nine scales was 0.87 (Meenan, 1982; 
Meenan, Gertman, \& Mason, 1980).

Longitudinally, AIMS results obtained from rheumatoid patients undergoing standard clinical care were found to be relatively stable over a 6-month period. This suggests "that any changes detected in an intervention trial might be due to the intervention, to regression towards the mean, or to some other effect other than instrument variability" (Meenan, 1982, p. 787).

These nine component scales were shown to be reasonably discrete, with high face validity, and readily understandable to both patients and health care professionals (Meenan, 1982; Meenan, Gertman, Mason \& Dunaif, 1982). Convergent construct validity ( $n=444$; $\mathrm{p}<0.001$ ) was provided when the scales were correlated with two physician generated estimates of health status: the American Rheumatism Association functional class (Steinbrocker et al, 1949); and disease activity. The correlations with functional class were found to be higher than those with disease activity (Meenan, 1982). A later study also demonstrated convergent validity for the health status construct (Brown et al., 1984). In a randomized crossover study $(\mathrm{n}=48)$, the AIMS was compared with another health status instrument, the Health Assessment Questionnaire (HAQ). Physical disability ( $r=0.91)$ and pain $(r=0.64)$ were found to be highly correlated, indicating the two measure similar constructs. The model, consisting of three postulated health outcome dimensions of pain, physical disability, and psychological status, was supported (Brown et al., 1984).

A clinical assessment of grip strength, walking time, joint count, and range of motion was also conducted on 114 subjects. The Pain Scale measure and the five scales that measure physical ability (Mobility, Physical Activity, Dexterity, Household Activities, and Activities of Daily Living) were highly correlated $(p<0.001)$ with the clinical assessments. When 
analyzed in multiple regression analysis, the nine scales together explained at least $60 \%$ of the variance in four summary health status estimates by patients and physicians. Similar reliability and validity results, with a few exceptions, were obtained when analyses were conducted for disease and sociodemographic subsets. This indicated that the instrument has broad applicability and generalizability across disease and demographic groups in a variety of clinical settings (Meenan, 1982; Meenan, Gertman, Mason \& Dunaif, 1982).

Single-scale factor analyses indicated that each set of the nine components (except Household Activities) loaded strongly on a single factor. This provided strong supportive evidence that each scale measures a single component of health status. An overall factor analysis, conducted with normalized scores for the scales, indicated there were three discrete factors. The first factor contained loadings from the five scales that measure physical ability (Mobility, Physical Activity, Dexterity, Household Activities, and Activities of Daily Living); the second factor had loadings from the socio-psychologic scales (Depression, Anxiety, Social Activity); the third factor had loadings from the Pain scales (Meenan, Gertman, Mason \& Dunaif, 1982).

A five-component model of health status as operationalized by the AIMS was proposed by a later study (Mason, Anderson, \& Meenan, 1989). Data obtained from the previously described study, pertaining to 82 subjects with $\mathrm{OA}$, was employed. Factor analysis of this data identified that $90.1 \%$ of the variance on the health status construct was explained by five factors: Lower Extremity (Mobility, ADL, Household Activity); Affect (Anxiety and Depression); Symptom (Physical Activity and Pain); Social (Social Activity); and Upper Extremity (Dexterity).

An earlier factor analysis, completed on data obtained from subjects with RA, 
indicated the same five components (Mason, Anderson, \& Meenan, 1988). Results were similar, however, the Pain subscale was associated with the Lower Extremity component for patients with RA. The activities involved in this component require more physically complex tasks than just walking and stair climbing (Physical Activity). Persons with OA typically present with hip and knee involvement. Their association of pain with ambulation activities (walking and climbing activities) suggests differing management of OA and RA pain. Pain for persons with RA may be more a manifestation of joint involvement, and less activity dependent (Mason, Anderson, \& Meenan, 1989).

The AIMS ability to detect meaningful health status changes over time was demonstrated by a controlled clinical drug study (Meenan et al, 1984). Subjective health measures were compared to standard clinical outcome measures in a double-blind, multicenter clinical drug trial. This 21-week study compared placebo, oral gold (relatively new drug), and injectable gold (established treatment) in randomly assigned patients with active RA $(n=161)$. Clinical, laboratory, and health status measures all produced comparable conclusions; both oral and injectable gold were shown to be more efficacious than the placebo. Significant improvements (range from $p<0.001$ to $p<0.032$ ) were measured in all nine clinical variables and all three lab tests (joint count for tenderness or pain, joint swelling, grip strength, physician and patient estimates of arthritis activity, urinalysis, and blood count). Significant differences $(p<0.05)$ were found between treatment groups change scores (pre-and post-treatment administrations) in five of the AIMS scales: Physical Activity, Anxiety, Depression, Pain, and Arthritis Impact. The physical dimension of health status was significantly (though not highly) correlated $(\mathrm{p}<0.01)$ with grouped clinical measures (joint tenderness, joint swelling, and grip strength). Less significant correlations $(p<0.05)$ were 
found with joint tenderness and grip strength and the pain dimension, and the psychological dimension and joint tenderness. In discriminant analyses, both the clinical and the AIMS measures displayed similar abilities to discriminate among the groups, and between treatment and no treatment (Meenan et al. 1984).

A later study (Potts \& Brandt, 1987) provided further evidence of the construct validity of the AIMS. Significant, though modest, correlations were obtained between selected subscales (Physical Activity, Dexterity, Pain, Anxiety, and Depression) and rheumatoid arthritis patients' $(n=120)$ ratings of the importance of various aspects of their treatment. Findings suggested that items on the household activity subscale might not be appropriate for use with men. Additional findings supported the researchers' hypothesis that the ADL subscale was insensitive to persons with mild impairment (Potts \& Brandt, 1987).

The above research studies have indicated known psychometric properties for the AIMS. Since its design, the AIMS has been employed in hundreds of empirical studies. This health status instrument displays proven reliability, validity, and sensitivity; all of which are required of a good outcome measure (Meenan et al. 1984).

AIMS2. The AIMS2 was designed to be a more comprehensive and sensitive version of the AIMS (Meenan, Mason, Anderson, Guccione, \& Kazis, 1992). Three new scales were added to evaluate arm function, work, and social support; scale items and names were revised; and sections were added to assess satisfaction with function, attribution of health status problems to arthritis, and designation of patient-selected priority areas for improvement. These changes haven't been shown to affect persons' ability to understand and complete this self-report questionnaire. Most patients have shown an average completion time of 20 minutes. Required reading ability is estimated at the fifth grade level (Meenan et al, 
1992).

This revised and expanded version was first pilot tested $(n=24)$, then performance tested with a sample of 408 subjects with RA or OA. Names of 797 eligible persons had been submitted by participating physicians at 13 clinical practice sites across the United States. A single mailing of questionnaires yielded a response rate of 51\%. Repeat AIMS2 questionnaires were mailed to the first 50 subjects within two weeks to determine test-retest reliability $(n=45)$. Intraclass correlation coefficients ranged from $0.78-0.94$ on scores obtained from the 12 scales and additional items. The Work scale score $(n=17)$ was the only reliability coefficient lower than 0.80 ; six of the remainder exceeded 0.90 .

The twelve scales of the AIMS2 include: Mobility Level, Walking and Bending, Hand and Finger Function, Arm Function, Self-care, Household Tasks, Social Activities, Support from Family and Friends, Arthritis Pain, Work, Level of Tension, and Mood. Mean scores for the RA and OA subjects did not differ substantially, except for the expected poorer scores on hand and finger function and arm function in the RA group. Internal consistency, as estimated by Cronbach's coefficient alpha, exceeded a threshold of 0.70 in both disorder groups; 0.72 91 in the RA group; $0.74-0.96$ in the OA group; for both, most coefficients were in the range of $0.80-0.89$. All within-scale factor analyses loaded on single factors, except for mobility level in OA. Factor analysis of the scale score variance identified that $50 \%$ or more was explained by the principal factor in all cases.

Validity testing was based on each subject's responses to other items in the questionnaire. Scores from subjects, who designated an area as a health status problem or as a priority for improvement, were significantly associated $(\mathrm{p}<0.001)$ with a poorer AIMS2 scale score in that area. Satisfaction was moderately correlated with function (range of 0.50 
to 0.69 in RA group; 0.42 to 0.68 in OA group) in the newly added AIMS section; test-retest reliability coefficient was 0.89 .

Reliability levels of the new versions of the AIMS scales, as well as the three newly added scales (Arm Function, Support from Family and Friends, and Work) were found to be comparable with those reported on the original version. Reliability, factor analysis, and validity results were consistently obtained across the two major disease groups (OA and RA), as well as across age, gender, and education subgroups. These results indicate good generalizability of scores.

\section{AIMS and Health}

Both AIMS instruments, as well as the majority of health status indices, base their operational definitions of health on the concept of functioning and the capability to perform daily activities (Jette, 1980; McDowell \& Newell, 1987). Parsons (1958) has defined health as "the state of optimum capacity for the effective performance of valued tasks" (as cited in Patrick, Bush, \& Chen, 1973, p. 8). Others have operationalized function in terms of performance rather than capacity (Patrick, Bush, \& Chen, 1973). A person is defined healthy if he is physically and mentally able to do the things he wishes and needs to do (McDowell \& Newell, 1987). An implicit assumption underlying these concepts is that an increase in dependence in the performance of activities equates to a loss of health (Jette, 1980).

\section{Occupational Therapy Theory and Health}

These concepts are consistent with the philosophical underpinnings of occupational therapy (Resolution 532-79, 1979) which rest on the premise that persons can influence the state of their health through participation in purposeful activity (occupation). Reed and Sanderson (1992) expressed assumptions underlying the theory and practice of occupational 
therapy regarding a human being: a person is a biopsychosocial and spiritual being, a unified whole that interacts in the environment as a total being, and an open system energy unit with a constant interchange of energy between the person and the environment. Further assumptions state: that through performance of occupations a person adapts to or adjusts the environment; that occupations are determined by environmental physical, biopsychosocial, and sociocultural needs and demands; that occupations are composed of knowledge, skills, and attitudes; and a balance of occupations is facilitory to the maintenance of health and quality of life (Reed and Sanderson, 1992).

Christensen (1991) organized these concepts into the Person-EnvironmentPerformance Framework. As an open system, a transaction or interplay occurs between individuals and their environment, each influencing the other in a reciprocal manner. Performance is altered in a dynamic fashion based on subjective judgments of changing environmental conditions and self perceptions of the meaning of those changes as they relate to well-being. West (1984) reaffirmed the philosophy of occupational therapy practice regarding occupational performance as the "mind-body environmental interrelationships activated through occupation" (p. 22). The person, as doer, is the product of unique and complex subsystems underlying performance. Motivations, beliefs, abilities, experiences, are higher order factors comprising the person in conjunction with the intrinsic performance enablers of sensorimotor, cognitive, and psychosocial skills. The environment consists of physical nonhuman aspects, as well as social dimensions, cultural influences, and public policy.

Nelson and Peterson (1989) theorize that desire for enhanced health or fear of disability is one of five possible motives elderly persons have for engaging in therapeutic 
exercise. Therapeutic exercise includes activities that are perceived as meaningful and purposeful to the individual. They frequently provide a naturalistic context for motivating and supporting healthy movement. Task-related social interactions are frequent side benefits (Nelson \& Peterson, 1989).

Dunn, Brown, and McGuigan (1994) proposed a new framework, the Ecology of Human Performance, expanding on Christensen's concepts. They included the contextual features of the environment as well as its interrelationships with persons and effects on performance. Context includes both the environment as defined by Christensen as well as temporal aspects: chronological, developmental, life cycle, period (span of time), and health status (American Occupational Therapy Association, 1994; Dunn, Brown, \& McGuigan, 1994). The added dimension of context incorporates factors external and unique to the person. Context is a critical factor in human behavior and performance.

\section{Therapeutic Exercise for Arthritis}

Authors of juvenile rheumatoid arthritis (JRA), ankylosing spondylitis (AS), and osteoarthritis (OA) chapters in Conn's current therapy: Latest approved methods of treatment for the practicing physician (Hittle et al., 1996; Lindsley, 1996; Thomson, 1996; Weaver, 1996) concur about the value of therapeutic exercise for these populations. An exercise program designed to improve general fitness, as well as a program of graded active isometric and isotonic exercises for involved joints, are considered to be an important component of arthritis treatment (Lindsley, 1996; Melvin, 1989; Thomson, 1996; Weaver, 1996). A balance of rest and activity is recommended, with necessary modifications of exercise during exacerbations. Therapeutic exercise is contraindicated during active inflammation (Hittle et al., 1996; Melvin, 1989). Lindsley, Thomson, and Weaver (1996) refer to goals that are 
common to all forms of arthritis: enhance general well being, maintain joint cartilage integrity, prevent muscle atrophy and osteoporosis, decrease muscle spasm, reduce pain, and help maintain a full range of motion (ROM) in joints. Pedretti and Wade (1996) add further goals of therapeutic exercise: improve voluntary, automatic movement responses; develop strength in order to increase work tolerance and physical endurance and prevent contractures; and improve coordination.

It is recommended that exercise should involve large muscle groups with a primary focus on joint ROM (Semble, 1995). Therapeutic exercise interventions need to be sufficiently effective to maintain or improve function, but should not cause exacerbation of symptoms (Heyneman \& Premo, 1992). Exercise to tolerance should be followed as a guideline, in addition to following supportive measures such as joint protection principles, energy conservation, and work simplification techniques (Hittle et al., 1996).

\section{Arthritis Foundation Program}

The Arthritis Foundation Aquatic Program (AFAP), is an organized community-based water exercise program the Arthritis Foundation co-developed with the Young Men's Christian Association (YMCA) in 1984. A specific protocol of gentle water activities are offered. Some Arthritis Foundation chapters also offer an advanced level program, AFAP PLUS, which incorporates more vigorous exercise to provide a longer endurance component (AF, 1996a; AFAP, 1990). Both programs are designed for persons with arthritis, sponsored by the Arthritis Foundation and offered in chapters throughout the U.S. by certified, trained instructors (AF, 1996a; AFAP, 1990; Tork \& Douglas, 1989).

The Arthritis Foundation advocates these non-clinical programs for persons with all forms of arthritis. According to Arthritis Foundation literature, stated physical goals for this 
form of exercise are to safely maintain range of motion in affected joints, as well as "it may result in some physical benefits such as decreased pain and stiffness" (AF, 1996a, p.1). AFAP PLUS activities are performed at low to moderate intensity to improve muscular strength and endurance with minimal risk of injury (AFAP, 1990). In addition, the Arthritis Foundation literature professes that AFAP's group water classes provide a supportive atmosphere. Participants can increase social interactions, decrease feelings of depression and isolation, increase independence, and improve sense of well-being and self-esteem (AF, 1996a; AFAP, 1990).

The Arthritis Foundation has very definite guidelines for their community-based aquatic program. They sponsor training workshops for class instructors in order to maintain consistency among the 65 chapters providing this service (AF, 1996; AFAP, 1990; Tork \& Douglas, 1989). Length of class sessions, time spent per exercise component, order and number of repetitions done per muscle group, and certain exercises are specified. AFAP protocol components include: warm-up range of motion activities for the neck and upper extremities (UE) with ensuing aerobic and endurance activities; slow stretching alternating with reciprocal movements of the lower extremities (LE); followed by slow stretching of UE, LE, and trunk; and a cool-down that incorporates ambulation activities with resisted exercise for the UE and trunk (AF, 1996a; AFAP, 1990; Tork \& Douglas, 1989).

\section{Water Exercise as Therapy}

Immersion in water, or balneotherapy, has been described as probably the oldest medical treatment on record; accounts describing its effectiveness date back to the Hippocratic era, c. 450-375 B.C. (Adler, 1993). Since World War I, aquatic therapy has been provided by occupational, physical, and recreational therapists in swimming and therapeutic 
pools as well as in Hubbard tanks (Johnson, 1988). In the twentieth century, Doctors Lowman and Roen published specific underwater treatment procedures. Their presentation of a film on underwater exercise at the American Orthopedic Association meeting in Atlanta, Georgia lead to the medical community's increased interest in pool therapy. President Franklin D. Roosevelt's treatments for poliomyelitis at Warm Springs, Georgia brought aquatic therapy to the public's attention (Moor, Peterson, Manwell, Noble \& Muench, 1964).

There has been a scarcity of empirical work over this long span of history despite claims of the curative powers of water (Adler, 1993). Fewer than 30 studies incorporating water exercise treatments were located in an extensive literature search conducted between the mid-1970's to present; the majority of studies were designed for an arthritic population. Most aquatic related research published in the English language had been conducted within this last decade; primarily in the United Kingdom and Scandinavian countries.

\section{Arthritis Foundation Aquacize Studies}

One study specifically referred to the Arthritis Foundation aquatic treatment program (Tork \& Douglas, 1989). A self-assessment survey evaluated the effectiveness of the Kansas chapter's AFAP. One-third of 600 AFAP participants responded to mailed questionnaires. Demographically, the majority of respondents were Caucasian (96\%), female (86\%), over age $65(54.5 \%)$, retired $(65.5 \%)$, with an income level of $\$ 20,000$ or more yearly $(32 \%)$ and had OA $(63 \%)$. Almost half the respondents had begun the aquatic program within the previous year; $30 \%$ had been in the program more than two years.

Self-assessments by the AFAP participants were all reported improved in three general categories; joint flexibility, muscle strength, and activities of daily living. Of these categories, the least improved mean score was in perceived effectiveness in muscle strength; "feel better 
about myself" received the highest mean score.

Former AFAP participants who had discontinued class attendance in the prior two years (25\%) offered physical complications or family commitments $(49 \%)$ as reasons for their discontinuation. Other reasons cited were poor class schedule, class organization, and poor class facilities (66\%), all of which are amenable to changes in program planning (Tork \& Douglas, 1989).

Meyer and Hawley (1994) compared 87 participants of six Kansas AFAP water exercise programs with 174 arthritis clinic patients not receiving any regular range of motion exercise and/or aerobic exercise. Two patients were matched to every one exerciser by age, gender, and type of arthritis. Demographic characteristics of the exercise group were similar to the earlier study: predominantly Caucasian $(96.9 \%)$, female (82\%), average age 68 , retired $(63.0 \%)$, a yearly income level at or below $\$ 15,000(43.7 \%)$, married $(70 \%)$, OA (72.4\%), and with a mean disease duration of 16.1 years. Duration of participants' AFAP attendance ranged from first time to 22 years, with $54 \%$ having joined during the prior three years. Average attendance was eight sessions per month. Demographically, there were no significant differences between the AFAP participants and clinic patients except for income levels $(60.4 \%$ reported incomes between $\$ 15,000$ and $\$ 50,000$ ).

Comparisons of functional disability, pain, grip strength, global severity of disease, anxiety, and depression were made. The patient group was found to significantly differ from the AFAP participants on all variables. The clinic attendees, particularly those with RA, demonstrated significantly higher disease severity as compared to the AFAP participants. As evidenced by the participants' pain and disability scores, the authors concluded that AFAP does reach persons with clinically important arthritis; however, the most severely affected 
persons were under represented in these community-based programs (Meyer \& Hawley, 1994).

\section{Physiological \& Psychosocial Effects of Water Exercise}

Various dynamic physical properties of water integrate to produce therapeutic effects on physiology. These are the forces of hydrostatic pressure, buoyancy, relative density, viscosity, and the thermal and mechanical properties of water. Taken separately, each one of these principals has known therapeutic outcomes for various conditions (Bates \& Hanson, 1992). However, there have been few clinically controlled trials (Swezey, 1993) documented to support these benefits.

The theoretical basis of aquatic therapy rests on the application of water's physical principles to movement. Harrison, Hillman, and Bulstrode (1992) studied nine unimpaired subjects to quantify the relationship between loading of the lower limbs when standing and walking at varying speeds while partially immersed to different levels in the water. The subjects' effective weight or percentage of static (standing) weight-bearing was found to decrease in proportion to the degree of immersion. Degree of immersion was related to anatomical landmarks: anterior superior iliac spine (ASIS), xiphisternum, and the seventh cervical vertebrae (C7). In hip deep water, the body is $43 \%$ weight-bearing; chest deep water reduces body weight to about $29 \%$ of land based weight; in shoulder deep water, the body is $85 \%$ weightless; thus neutralizing the effects of gravity. The percentage of weight bearing at equal depths increases with both slow pace and fast walking in water (Harrison et al., 1992). Resistance is increased by varying the intensity and speed of movement. This study has important clinical implications for aquatic therapists in order to avoid exceeding permitted degrees of weight-bearing during exercise. 
In addition to physiological benefits, participation in aquatic activities has been found to "provide opportunities for people with chronic or acute physical dysfunction to take an active role in the management of their physical and psychological status" (Johnson, 1988, p. 117). The feeling of freedom, relaxation, and pain relief obtained from water exercise has been found to offer important psychological value; this leads to overall effectiveness (Swezey, 1993).

\section{Studies of Physical Effects}

Two studies report mixed results regarding the physical effects of aquatic exercise on persons with arthritis (Hansen, Hansen, Langgaard, \& Rasmussen, 1993; Green, McKenna, Redfern, \& Chamberlain, 1993).

Mixed results. Hansen, Hansen, Langgaard, and Rasmussen (1993) looked at the longterm effects of physical training on persons with RA. Using a total of 75 patients (median age 52) as subjects, they measured numerous variables: morning stiffness, pain score, number of swollen joints, a health assessment score, functional score, erythrocyte sedimentation rate (ESR) and blood hemoglobin $(\mathrm{Hb})$, cost of medicine, and progression of disease using X-rays of hands and feet. Subjects were randomized to one of five treatments: (a) patients received written instructions for a 15 minutes overall training program, followed by 30 minutes of conditioning, to be done as self training a minimum of three times a week; (b) as A, plus 30 minutes of training with a physical therapist, once a week, using a bicycle for conditioning; (c) as A, plus weekly small group training in the hospital, also using a bicycle for conditioning; (d) as C, but conditioning training involved aquatic exercise; and (e) controls received no instruction in training. All participants were examined by the same physician and physical therapist who were blinded observers to subjects' assigned treatment group. At 
conclusion of the two year trial, all patients answered a questionnaire to subjectively evaluate their training, followed by an interview about their physical activities during the study.

There were no statistically significant effects of training on any of the measured variables. The authors hypothesize that these results may be due to a relatively small number of patients in each group, or to insufficient type or intensity of training. Though the effects were not significant, muscle strength increased in all groups. There was no change in aerobic fitness. There was a general progression over time in joint destruction in all groups, as evidenced in X-rays, as well as a decline in functional score. The authors conclude that long term training programs for RA patients don't appear to be harmful, but neither are they helpful for inflamed joints.

The subjective questionnaire and interview at the completion of the trial indicated that $66 \%$ of all patients reported a general improvement in disease activity and well-being. Twenty-five percent wanted to continue training, but at a higher intensity. Again, no statistically significant differences were found between groups. The authors state that outcome measures regarding quality of life, depression, and anxiety would have been better indicators to detect general satisfaction with exercise training (Hansen et al., 1993).

Green, McKenna, Redfern, and Chamberlain (1993) concluded that home exercises are as effective as outpatient hydrotherapy for persons with hip $\mathrm{OA}$. They examined objective measures (ROM, strength), subjective measures (pain, need for medications), and functional measures (ability to rise from chair, time and number of steps taken to walk a fixed distance, and time taken to walk up and down a staircase). Forty-seven persons with OA were randomly assigned to one of two treatment groups: a program of home exercises performed twice daily (five types of exercises designed to improve joint mobility and increase muscle 
strength); or home exercises also performed twice daily plus twice weekly hydrotherapy for six weeks. The types of exercises used for water therapy were not mentioned. Participants were assessed every three weeks during the study by a therapist blind to treatment assignment and prior assessments. All subjects kept a log, which was reviewed at each assessment to verify compliance with their home exercise routine.

At weeks nine and 12 , both treatment groups showed statistically significant outcomes as compared to baseline measures: decreased immobility stiffness; number of steps taken to walk a fixed distance; time taken to walk up a fixed staircase; increased measurements of hip external rotation, hip adduction power, and endurance;. There were no significant differences in any of the variables in response to either of the two treatment groups. The study does indicate that patients who participated in the water exercise treatment did show significant improvements in both objective and subjective measures. The authors contend there is no additional benefit from the addition of hydrotherapy versus home exercise. They do allow that these results may have been due to errors in design: that twice weekly hydrotherapy treatments may not be sufficient time to produce effects; that patient compliance may have affected results; and that selected patients may still benefit from exercise in water (Green et al., 1993).

Strength. Use of the natural resistance of water during exercise has been shown to assist in building muscle tone, endurance, and strengthening of large muscle groups (Danneskiold-Samsoe, Lyngberg, Risum \& Telling, 1987; Stenstrom, Lindell, Swanberg, Swanberg, Harms-Ringdahl, \& Nordemar, 1991).

A long-term study of the effects of intensive dynamic training in water was published by Stenstrom, Lindell, Swanberg, Swanberg, Harms-Ringdahl, and Nordemar (1991). Thirty 
persons with RA, functional class II, were selected to receive four years of water exercise training. A control group (CG), who received traditional physical therapy with static ROM exercises, was matched by age, gender, and duration of disease with the treatment group (TG). The TG received the same physical therapy regime as the control group, plus once weekly intensive water training for 40 minutes. Subjects completed questionnaires prior to the training period, twice yearly during treatment, at completion of the training, and two years after completion.

The only direct training effect found, possibly due to the low (once a week) frequency of aquatic treatment, was in grip strength. The TG showed significant improvement in this UE measure; however, grip strength had deteriorated in the CG. The difference between groups reached statistical significance for the right hand only.

Participants realized additional motivational benefits from the aquatic training. The TG reported significantly improved activity level regarding other forms of exercise (ie. swimming, fast walks, jogging), which was maintained at two-year follow up. On the posttraining questionnaire, and at the two-year follow up, $15 \%$ and $7 \%$ of the TG as compared to $57 \%$ and $59 \%$ of the CG stated they never or seldom exercised.

The most frequent positive judgements given by the TG regarding their training were: "increased sense of well-being during and/or after the training", "decreased feeling of stiffness", "possible to perform things that are impossible when not in water", and a "feeling of joy and security together with other rheumatics, health care staff, and physiotherapist" (Stenstrom et al., 1991, p. 362). Though many TG participants reported an increase in pain during and after the water exercise sessions, they still had a positive attitude about their training. 
No undesirable effects from the intensive training were seen in this RA population. No significant differences were reported between the two groups regarding medication usage, or joint tenderness, swelling, or destruction. There were significantly more CG patient acute hospital care admittances for their rheumatic disease during the training period. Long-term success was evidenced by the participants' increased activity level without any actual decrease in activity-induced pain (Stenstrom et al., 1991).

Another Scandinavian study (Danneskiold-Samsoe, Lyngberg, Risum \& Telling, 1987) involved eight persons with rheumatoid arthritis, functional classes II or III, in twice weekly 45 minute water exercise sessions for two months. Intensity of exercises was individually adapted to account for each subject's pain threshold and fatigue. Additional individual hip and leg muscle resistance training was given; the authors did not state the amount.

Isometric and isokinetic LE muscle strength were measured in this group, and compared with eight gender and age-matched healthy untrained control subjects. The controls were not given any exercise training. Using non parametric methods to test for significance, the RA patients showed significant gains in isometric ( $38 \%$ increase from pre to post-training) and isokinetic quadriceps strength $(16 \%)$ at low angular velocities. No significant differences were seen when measuring at high angular velocities. Isometric muscle strength of the RA patients did not reach normal values after 2 months of training; their pre-exercise values were $39 \%$ lower than the healthy control subjects'. Muscle strength measurements taken two months after the end of training were greater than prior to training, but not significantly.

The pre-exercise maximal isokinetic muscle strength of RA subjects was also significantly lower $(30 \%)$ than controls. Strength measurements taken two months after the end of training had decreased, but were still $30 \%$ greater than prior to training; again not 
significantly.

No side effects (flares or exacerbations of RA) from exercising in water were reported. Several patients did report a higher degree of abilities in performance of ADLs and more freedom to move after training. Also measured were significant increases in oxygen uptake from pre to post exercise, as indicated by increased aerobic capacity, were also measured (Danneskiold-Samsoe et al., 1987).

Range of motion. Two studies reported increases of ROM in persons with arthritis as a result of aquatic exercise treatments (Bacon, Nicholson, Binder, \& White, 1991; Rasmussen \& Hansen, 1989).

Bacon, Nicholson, Binder, and White (1991) studied 11 children between the ages of four to 13 with juvenile rheumatoid arthritis, functional classes I-III. This six week nonrandomized and noncontrolled pilot study measured the effects of aquatic exercise on lower extremity range of motion and strength, gait, balance, heart rate, and functional mobility. One hour long exercise sessions were held twice weekly, including 45 minutes of structured exercise in midchest water depth, followed by 15 minutes of "free play" time in the pool. The exercise regimen included a warm-up phase with slow static stretching, lower extremity range of motion strengthening exercises, and a cool-down phase with slower movements and gentle stretching.

Reported were significant improvements in bilateral external and internal hip rotation in addition to significant improvements in right hip flexion, and knee extension. Nonsignificant improvements were seen in bilateral foot plantar flexion, and in the median scores for balance and timed tests. Gait analysis also reported non-significant improvements in velocity, cadence, and stride length. Median heart rate, taken immediately following the more 
vigorous phase of exercise, increased as the program progressed, indicating greater effort. A pattern of fuller recovery within five minutes after vigorous exercise was seen to be significantly increased by the end of the six weeks when differences between pre-exercise and cool-down heart rates were compared. The JRA participants tolerated the exercise without increased discomfort or exacerbation of symptoms. The children subjectively reported having enjoyment in the activity, fun with group socialization, and desire to continue their exercises (Bacon, Nicholson, Binder, \& White, 1991).

Ankylosing spondylitis is typically first diagnosed between the ages of 20 and 30 . This form of arthritis often causes severe restrictions in functional ability. Few studies have examined the effects of physical activity treatments as a method to delay or halt the progression of disability. Two pilot studies measured the effects of aquatic exercise on persons with AS.

The first was a preliminary report by Danish researchers, Rasmussen and Hansen (1989), on an ongoing long term hospital physical training program. One to three weeks of inpatient care were given to 47 persons with AS, followed by weekly outpatient group training sessions, lasting one and $1 / 2$ hours per session. These group sessions included 45 minutes in a heated pool doing flexibility and strengthening exercises for back, hips, shoulders, and chest expansion; a 15 minute interval for feedback and assessment by the therapist; followed by 30 minutes of similar land based exercises and five minutes of relaxation exercises. Measured outcomes were mobility, motivation to continue exercise program, and effects of group support. An evaluation was completed every six months to measure cervical range of motion, chest expansion, spine and hip flexibility. Patients were followed from three to more than five years. 
Rasmussen and Hansen (1989 reported, citing no statistical results, that mobility measures taken at the start of treatment, after one year, and after five years remained stable for those 18 patients who had been participating in the program for more than five years. Weekly attendance rate of the 47 patients with AS was $80 \%$. Twenty-five had been attending for more than three years and, as mentioned previously, 18 for more than five years. Of the 14 patients who had jobs at the start of treatment, none had to give up working. The authors conclude that regular physical training has a stabilizing effect on AS, helps to maintain mobility, and prevent further deterioration. No further articles have been published to date on this study.

Pain. A second uncontrolled pilot study that used hydrotherapy in the management of AS was conducted by Smit and Harrison (1991). Twenty persons with chronic lower back pain from AS (mean age: $59 \pm 14.3$ years; mean duration of pain experienced: 9.6 years \pm 8.0 years) were given three individual 30 minute aquatic exercise sessions per week for four weeks. At completion of the treatment program, a home exercise program was provided to maintain strength and mobility. Variables measured were: thoracolumbar mobility, degree of pain (level experienced over last 6 months, and at time of treatment), and amount of pain medications. Pre and post intervention measurements and self-report questionnaire were given three months after conclusion of treatment.

There was found to be a statistically significant improvement in thoraco-lumber mobility noted pre to post intervention. Eighty-four percent of the persons with back pain increased ROM in one or more directions, $16 \%$ in all planes. The three patients who had exhibited levels of spinal mobility below normal ranges pre treatment were within normal ranges post treatment. It appeared that those subjects with the most severe restrictions prior 
to treatment benefited the most from treatment.

A highly statistically significant decrease in pain levels from pre to post intervention was reported; $74 \%$ of the participants reported a reduction, none reported an increase. However, this pain reduction didn't last; results from the questionnaire given three months after the conclusion of treatment indicated that pain levels had significantly increased from post-treatment levels. Despite this increase, $77 \%$ reported feeling better or much better than prior to treatment, with only one subject reported feeling worse. This suggested there was an enhancement of overall health and subsequent quality of life, but continuing programs are needed to maintain gains (Smit and Harrison, 1991).

DeVylder (1995) described an informal case study of a woman with chronic neck, leg, and back pain due to degenerative joint disease. Nine aquatic physical therapy sessions were given (length of time not given) in conjunction with a home exercise program (no information about this program). The woman reported increased function in activities of daily living; she could now accomplish vacuuming and heavy lifting. Prior to the classes, pain had limited her to 15 to 20 minutes of standing and walking. She reported that she felt a $100 \%$ improvement. She no longer had pain in the morning, no longer had paresthesia, and no spasms were noted. The therapist measured increased ROM in cervical spine, trunk flexion, hamstring flexibility from initial evaluation as well as increased UE and LE muscle strength (DeVylder, 1995).

Aerobic effects. Results from Minor, Hewett, Webel, Anderson, \& Kay's 1989 study indicated that persons with RA and OA can participate in physical conditioning exercise without causing an exacerbation of joint disease. One hundred and twenty patients were randomized to one of three exercise program groups: aerobic walking, aerobic aquatics, and non-aerobic range of motion (controls). All were given individualized prescriptions for 
exercise to be done in groups for one hour three times per week. Treatment length was 12 weeks, with follow up evaluations at three months and nine months. Within group, and between group change scores were used to test for differences in this two factor experimental design (exercise group and time).

Both aerobic conditioning treatment groups showed significant improvement (20\%) in aerobic capacity at 12 weeks compared with baseline and compared with control group (no change). 50-foot walking time, depression, anxiety, and physical activity (AIMS) scores improved significantly for the aerobic groups; these changes were significantly different from those of the control group after 12 weeks of exercise.

When tested at the end of 12 weeks, the pool group showed significant improvement in the number of clinically active joints, duration of morning stiffness, and grip strength over their baseline disease-related measures. This compared to the walk group, which only showed significant improvement in grip strength. The pool group also showed significant improvement at 12 weeks from baseline in AIMS scores, physical activity, and physical selfconcept scores. However, no significant differences were found between the change scores of the treatment groups and control group for flexibility, number of clinically active joints, duration of morning stiffness, or grip strength

All treatment groups were further examined according to type of arthritis. The RA group showed significantly higher mean number of clinically active joints, duration of morning stiffness, dexterity, and social activity scores and lower grip strength scores than the OA group. There was no change in intensity of drug treatment for their arthritis symptoms for most subjects, indicating there was no exacerbation of arthritis signs and symptoms.

The pool group maintained their post intervention changes over baseline at the three 
month follow-up, except for duration of morning stiffness, anxiety, and depression. Improvements in aerobic capacity, exercise endurance, 50-foot walking time, grip strength, flexibility, and physical activity continued to be maintained at nine month follow-up for the two aerobic conditioning groups. Sixty-three percent of all subjects reported continuing with at least 60 minutes of exercise per week at three-month follow-up, with a drop to $57 \%$ at nine-month follow-up (Minor et al., 1989).

Osteoporosis. Tsukahara, Toda, Goto, \& Ezawa (1994) conducted a cross-sectional and longitudinal study on the effect of water exercise in controlling bone loss in Japanese postmenopausal women. Three groups were compared: a control group of non-exercisers $(n=30)$, newcomers to a community water exercise class $(n=40)$, and veterans of the class ( $n=27$ with 35.2 months average exercise history). The exercisers participated in a 45 minute class session performed at least once weekly. Bone mineral density (BMD), sufficiency rates of nutrients based on a three day diary, physical characteristics of subjects (age, height, body weight, body mass index, and \% body fat), and a general awareness survey were measured pre and post-trial, one year after the beginning of the study

Cross sectional results indicated that there were no significant difference in sufficiency rate of nutrients or physical characteristics between groups, except the veterans group was significantly older than the non-exerciser group. At pre-trial, the bone mineral density of the veterans' group was found to be significantly higher than that of the other two groups.

Longitudinally, after one year, the non-exerciser group showed a $2.72 \%$ decrease in $\mathrm{BMD}$, while the two exercise groups maintained or showed increased BMD levels $(0.75 \%$ newcomers, $0.27 \%$ veterans). A decrease of one to two percent a year is reported to occur in menopausal women. The results indicate that moderate physical exercise, performed as 
water exercise, can possibly increase bone mass and have a suppressive effect on bone loss, thus preventing the occurrence of osteoporosis.

As reported on a general awareness survey at completion of the trial, the participants claimed the water exercise program indirectly improved their awareness of state of health and improved their daily life. Over $70 \%$ of the exercisers reported they had an increased consciousness of their health (Tsukahara et al., 1994).

\section{Psychosocial and Functional Benefits}

Many of the previously mentioned studies reported psychosocial benefits due to exercise in water (Bacon et al., 1991; DeVylder, 1995; Hansen et al., 1993; Minor et al., 1989; Stenstrom et al., 1991). Even more of these previously cited studies measured functional changes or discussed self-reports of increased abilities (Danneskiold et al., 1987; DeVylder, 1995; Green et al., 1993; Minor et al., 1989; Rasmussen \& Hansen, 1989; Stenstrom et al., 1991). A statement by C. A. Trombly (1989) seems to define why people receive benefits from exercise in water:

The use of activity for stretching is empirically based on the idea that a person involved in an interesting and purposeful activity will gain greater range because he is relaxed, not anticipating pain, is motivated to complete the task, and will be more likely to move as the activity demands. (page 290)

Function. Fifty persons with chronic, painful conditions ( $78 \%$ neck and back pain, $10 \%$ arthritis, $10 \%$ fibromyalgia, $2 \%$ rotator cuff pain) were given pre and two month posttreatment self-assessment questionnaires to evaluate the benefits of an aquatic exercise program (Olsen, 1995). These randomly selected patients were evaluated by a therapist, given instructions for a water exercise program, provided with access to a heated pool, and 
encouraged to continue their program independently. Pre and two month post treatment questionnaires were completed by each person. The average number of sessions each patient received with a therapist was 4.94 sessions. Subjects in this informal self-report study reported reduction of pain medication usage, increased independence in ADLs, increased hours of sleep, and increased hours of work. Seventy-five percent of the participants reported they continued their exercise programs after therapy concluded (Olsen, 1995).

Mood. Participants enrolled in a Hydro-Cal-Aerobics water program were studied by Weiss \& Jamieson (1987). Eighty-eight women, ages clustered around 45-64 (range of ages 21 to 75 ) had been involved in this program from eight weeks to five years. These women were given an anonymous questionnaire regarding: a) motivation to enroll in class, b) motivation to continue, c) if the class was considered a support group, d) conversation issues with other members of the class, and e) preference for age-integrated class.

The primary reason given by all age groups to enroll was for exercise; those over the age of 35 added that the exercise was appropriate in relation to health related concerns. Other motivations stated were (as varied by age): weight control ( $36 \%$ were under 45 ); influence of others, such as spouses or physicians ( $20 \%$ of those over 65$)$; water-based program ( $30 \%$ of those over 65); and for mental health or reduce stress (those under 35).

All age groups reported exercise as their primary motivation to continue with the program. Having a positive experience and other psychosocial reasons such as camaraderie, importance of weight control and appearance, instructor's role, and viewing the program as a support group were also reported. These responses indicated increased involvement and commitment of the participants to the class.

Sixty-seven percent of those below $45,68 \%$ between ages $45-54,71 \%$ between ages 
$55-74$, and $89 \%$ of those 65 years and over viewed the program as a support group. Conversation topics include: humor; recipes, nutrition, and food; affective topics such as feelings and minor irritations; and entertainment. The vast majority (96.5\%) were in favor of age-integrated classes. They cited that the mixture made the classes more interesting and all benefited from ideas exchange. Because water is the "great equalizer" the authors advocated age-integrated classes for aquatic programs (Weiss \& Jamieson, 1987).

The same authors (Weiss \& Jamieson, 1989) performed a retrospective study on the above mentioned study. They specifically looked at twenty-one of the 88 participants enrolled in the Hydro-Cal-Aerobics water program. These women had subjectively reported on the anonymous questionnaire that depression was present at time of their enrollment in the water exercise program.

One hundred percent of these depressed women reported improvement in their depression as a result of the exercise program. The majority $(90.5 \%)$ credited the program for contributing to their improved emotional state. When comparing these women with the remainder of the class, it was found that both groups reported exercise and fitness as their major motivation to enroll in the class. However, the depressed individuals were significantly more likely to report exercise as their major motivation to continue with the program versus physical problems or mental health.

These depressed women reported significantly more numbers of problems than the nondepressed group in three areas: a) lifestyle habits of concern, which included inclination to worry, tension, and concern with eating patterns; b) physical problems, which included overweight, flabby muscles, stiffness/poor flexibility, fatigue and sleep-related problems; and c) emotional concerns of lack of accomplishment, physical neglect of self, emotional neglect 
of self, and feelings of guilt. The number of medical problems reported by the two groups didn't significantly differ. More than half $(54.4 \%)$ of the depressed group, as compared to $18.2 \%$ of the non-depressed, reported no other organizational or associative ties. This result suggests that the water program fills this void in their lives and provides social interaction. Finally, $42.9 \%$ of the depressed women, as compared to $16.4 \%$ of the nondepressed, reported that they learned "much" about relaxation, an outcome that would contribute to reduction of their reported symptoms or concerns (Weiss \& Jamieson, 1989).

Learning was an important aspect of the following study. Burckhardt, Mannerkorpi, Hedenberg, \& Bjelle (1994) performed a randomized, controlled clinical trial of education and physical training for women with fibromyalgia (FMS). The objective of this study was to measure the effectiveness of education, cognitive-behavioral techniques, and physical conditioning training (including two pool therapy sessions) in decreasing FMS symptoms and increasing physical and psychological well-being. Ninety-nine women were randomly assigned to one of these three groups: a six week self-management education program; that program plus 6 hours of physical training designed to assist them to exercise independently; or an untreated control group. A pretest-posttest design was used with testing done at baseline, at 12 weeks (six weeks after completion of experimental treatment), and at six months. Four self-report questionnaires were employed, Fibromyalgia Impact Questionnaire (FIQ), Fibromyalgia Attitudes Index (FAI), Quality of Life Scale, and the Self-Efficacy Scale. Physical fitness (distance walked in six minutes, flexibility of lower back, number of times able to rise from chair in one minute), the Beck Depression Inventory $\&$ tender points were also measured.

There were significant differences in change scores pre to posttest between the two 
treated groups and the control group in four variables: quality of life; and self-efficacy for function, pain, and other symptoms. The treatment group that received both education and physical training made positive changes on the FAI, indicating a greater sense of control over their disease. This group also showed improvements on all three subscales of the self-efficacy scale, indicating increased beliefs in their ability to accomplish specific tasks. No significant changes were seen in tender points and in physical fitness scores pre to post-test; probably due to the short time length of the study.

On long term follow up, $71 \%$ of the experimental subjects reported that the program had a positive impact on their symptoms. The majority (87\%) continued to exercise at least 20 minutes for at least three times per week. Almost half (46\%) reported they had increased their exercise level since participating in the program. Health status, as measured by the FIQ and Self-efficacy scales, significantly increased in the education and exercise group at longterm follow up. This result is important because it shows that education can play an important role in increasing patients' ability to cope with chronic diseases (Burckhardt et al., 1994).

Berger and Owen (1983) used the Profile of Mood Survey (POMS) to detect changes in mood before and after exercising. One hundred college students (mean age 22.3), voluntarily enrolled in swimming classes ( 25 beginners; 33 intermediate swimmers) were compared with 42 control subjects enrolled in lecture classes for the length of one semester (14 weeks). ANOVA statistical measures were used to investigate whether swimming skill level and gender had any effect on mood change.

Swimmers reported less tension/anxiety, depression/dejection, anger/hostility, confusion/bewilderment, and more vigor/activities after exercising than before. Both beginning (leisurely paced) and intermediate (strenuous exercise) swimmers experienced the 
same benefits in mood change. No gender differences were found in the amount of mood change with swimming. Women reported significantly less tension-anxiety, depression, anger, and confusion than the men. These mood changes were not seen with the control group. The authors reported that these results are similar to those reported in running research (Berger \& Owen, 1983).

Weinstein (1986) also used the Profile of Mood Survey (POMS) as a measurement tool. Participants reported less tension, depression, anger, confusion, and more vigor after swimming treatment than before (Weinstein, 1986).

\section{Summary of Literature Review}

This literature review was conducted focused on pertinant issues between the mid 1970 's to the present. It has indicated there remains a scarcity of scientific research conducted using water exercise in treatment. Most studies have been limited by small sample sizes, short lengths of treatment, and lack of control groups. Despite these limitations, significant physiological benefits have been documented in ROM, muscle strengthening, aerobic capacity, and pain reduction. This has been accomplished without further exacerbation of arthritis signs and symptoms.

Participants of aquatic programs report that the gained psychosocial benefits are what motivate them to continue their exercise regimes. Improved function and resultant quality of life, decreased depression, and increased self-efficacy all have been shown to result in increased performance.

The philosophical basis of occupational therapy rests on the relationships among occupation, function, and health. The focus of interventions by health care professionals is on maintenance or improvements in function, quality of life, and performance. Similar 
relationships are measured with various health status instruments. Based on the WHO definition of health, these measures focus on the physical, social, and mental components of health. Several health status measures have been shown to have proven reliability, validity, and sensitivity to measure improvements produced by therapeutic interventions. The AIMS2 self-report questionnaire is a newly revised instrument that was designed with that purpose in mind. 


\section{CHAPTER III}

\section{Research Methodology \\ Research Hypotheses}

The purpose of this study was to determine if participation in Arthritis Foundation sponsored water exercise classes can influence health status in older community living persons with various forms of arthritis. The principal investigator tested the following research hypotheses:

1. Regular participation in Arthritis Foundation sponsored aquacize classes will be effective in improving health status of older persons with arthritis.

2. Older persons with arthritis, after regular participation in Arthritis Foundation sponsored aquacize classes, will report more improvements in health status than a comparison group also regularly engaged in various types of therapeutic and rote exercise.

\section{$\underline{\text { Subjects }}$}

Demographic information was obtained for each subject from the AIMS2 measurement instrument: age, gender, racial background, marital status, educational level completed, employment status, economic status, type of arthritis, medication usage, and comorbidity. The principal investigator had added additional questions to the first page of the questionnaire booklet. This requested information was pertinent to determining subjects' eligibility for the study as well as ascertaining prior participation in therapeutic and rote exercise and aquacize exercise.

A convenience sample of nine experimental and eleven comparison group subjects, all community living persons with various forms of arthritis, was used. The experimental group was drawn from an Arthritis Foundation sponsored aquacize class. Experimental group 
subjects had already chosen to exercise in the Arthritis Foundation sponsored aquacize classes before commencement of this study. Senior volunteers from the local community were the source of the comparison group. All eligible participants meeting selection criteria were involved in this study.

\section{Subjects' Selection Criteria}

Inclusion criteria. For inclusion in this study, subjects must have met the following criteria:

1. Subjects must be 55 years old or older.

2. Subjects must have been diagnosed, or in some way informed by their physician, they have some form of arthritis.

3. Subjects must be able to read and write English.

4. Subjects must be willing to complete the self-report questionnaires.

5. For the experimental group, subjects must be able to commit to participation in the exercise program for eight consecutive weeks (attend at least 12 out of 16 sessions, and participate a minimum of 45 minutes out of a 60 minute session).

6. For the experimental group, subjects must not be involved in an ongoing regular exercise routine other than the Arthritis Foundation sponsored water exercise class (for example running, jogging, walking, gardening, swimming, bicycling, aerobic exercise, dancing etc.) more than ten hours per week.

7. For the comparison group, subjects must not be involved in an ongoing regular exercise routine (for example running, jogging, walking, gardening, swimming, water exercise, bicycling, aerobic exercise, dancing, etc.) for more than ten hours per week.

8. For both groups, subjects must not have any condition where exercise is not 
possible or contraindicated.

9. For both groups, subjects must sign the consent form.

\section{Design of the Study}

A quasi-experimental two-group pre-post test design was used for this study. The independent variable was participation in aquatic exercise, while the dependent variable was perceived health status, as measured by the twelve scales of the Arthritis Impact Measurement Scales 2 (AIMS2): Mobility Level, Walking and Bending, Hand and Finger Function, Arm Function, Self-care, Household Tasks, Social Activities, Support from Family and Friends, Arthritis Pain, Work, Level of Tension, and Mood.

\section{$\begin{array}{lll}\text { Comparison Group }= & 0_{1} & \mathbf{0}_{2}\end{array}$ Experimental Group $=\begin{array}{lll}\mathbf{0}_{3} & \mathrm{X} & \mathbf{0}_{4}\end{array}$}

$0_{1}=$ Pre-test on the twelve scales of the AIMS2.

$\mathrm{O}_{2}=$ Post-test on the twelve scales of the AIMS2.

$0_{3}=$ Same as $0_{1}$.

$\mathrm{X}=$ Aquacize for a period of eight consecutive weeks, twice per week for an hour

$\mathrm{O}_{4}=$ Same as $0_{2}$.

\section{Background Information on Experimental Group}

The Arthritis Foundation aquacize class resumed on April 1, 1997 after a four-month winter hiatus. The instructor had discontinued classes during the winter months due to cool air temperatures and inadequate pool water temperature, which often causes discomfort to persons with arthritis. Many persons who had previously attended in the fall of 1996 had 
returned to the aquacize class, as well as new participants who had joined the group. Aquacize classes were offered on an ongoing basis; this contrasted with some Arthritis Foundation instructors who require continuous enrollment in six to eight week sessions.

The same Arthritis Foundation certified instructor led all classes. She had received extensive training and certification from the Arthritis Foundation three years previously. The Arthritis Foundation YMCA Aquatic Program (AFAP) requires their instructors to follow specific guidelines. AFAP specifies 68 different aquatic exercises: gentle water activities designed to maintain or increase flexibility and strength. The instructor varied these exercises within each class session, a minimum of 21 exercises were included in each session. The instructor also varied music and social activities from class to class.

Aquacize classes were held twice weekly (Tuesdays and Thursdays), at the same location, and at the same hour (11:15 a.m.-12:15 p.m.). Palm Beach County Parks and Recreation Department owns and operates the heated outdoor Olympic sized pool (North County Aquatic Complex) and charges minimal class fees (\$1.50) to the public. According to the Pool Director, water temperatures during the study period (April to August, 1997) were maintained at an average of 84 degrees Fahrenheit (D. Comely, personal communication, November 26,1997$)$.

\section{Data Collection Techniques}

The principal investigator was available immediately prior to commencement of the first class to explain the nature of the study, the selection criteria, expectations, and to invite persons to participate. Study participants attended aquacize classes along with persons who had not volunteered to participate. The North County Aquatic Complex Pool Director had donated two free class sessions to all study participants as an incentive. All interested and 
eligible subjects reviewed and signed informed consent forms and sign up sheets. A list of the names, questionnaire identification numbers, and telephone numbers of subjects was maintained; this was kept separate from the questionnaires in a locked file.

Upon enrollment, the principal investigator gave each member of the experimental group a coded envelope with each subject's identification number on the outside. This envelope contained an AIMS2 questionnaire to complete on site after class, or at home, and was returned to the instructor at the following class. As new participants joined the classes throughout the spring and summer (April to August of 1997), the primary investigator or the instructor enrolled them in the study immediately following their first class session. The aquacize instructor maintained an attendance list at each class session during the eight-week study for each participant. At completion of the eight weeks, the principal investigator or instructor again gave eligible participants a coded envelope containing the AIMS2 questionnaire that was completed on site or at home. The instructor collected these questionnaires at the following class session.

Potential comparison group subjects were senior volunteers recruited from the local community throughout the spring, summer, and fall (April to November, 1997). Various methods were employed to recruit possible participants: posters were left on bulletin boards at various sites (grocery store, post office, local community events, senior recreation centers, senior condominiums, health fair, and hospital auxiliaries), and numerous personal appeals were made at senior gatherings. Respondents were informed they would receive five dollars for completing the two surveys. The principal investigator determined subjects' eligibility based on subjects' selection criteria and obtained informed consent via telephone contact or in person. Subjects were given or mailed informed consent forms and coded AIMS2 
questionnaires to complete and retum to the principal investigator. At completion of the eight weeks, the principal investigator again gave or mailed eligible participants a coded envelope containing the AIMS2 questionnaire that was completed on site or at home and returned to the principal investigator.

\section{$\underline{\text { Statistical Data Analysis }}$}

The AIMS2 instrument includes 78 items: four or five items/questions comprising each of twelve scales, demographic questions, and additional questions referring to overall health. All scale questions were scored in a consistent fashion, with a low value indicating a high health status. To avoid systematic response bias, some response arrangements were mixed and then recoded in the proper direction prior to calculation. After recoding, the raw scores of every item within the scale were added together. A normalization procedure was then performed in order to express all scores in a range of $0-10$, with 0 representing good health status and 10 representing poor health status. Normalization procedures were also performed on several of the additional questions.

The authors of the AIMS2 (Meenan \& Mason, 1994) allow a scale score modification to adjust for the fact that health status problems in a particular area of function may be due to problems other than arthritis. Each AIMS2 scale score can be multiplied by differing factors based on subject's response to question 59, attributing problems with each area of health to arthritis. Adjusted values can be used when sample population age is reported as greater than 60 and comorbidity totals greater than two. Condition one was met because all participants reported they were older than 60 . However, condition two was only partially met by the experimental subjects. Therefore, this researcher opted not to utilize arthritis adjusted scores for the tests on the twelve scales. 
A five component model of arthritis adjusted health status was calculated using AIMS2 scale scores. Individual scales within each component were normalized and adjusted prior to any component grouping as specified in the AIMS2 User's Guide (Meenan \& Mason, 1994).

Table 1

Derivation of Five Component Model of Health Status

\begin{tabular}{|l|r|}
\hline Component & \multicolumn{1}{c|}{ Scale Items } \\
\hline Physical & $=($ Mobility Level + Walking \& Bending + Hand \& Finger + Arm \\
& $\quad$ Function + Self-Care Tasks + Household Tasks $) \div 6$ \\
$=$ & $($ Level of Tension + Mood $) \div 2$ \\
Affect & $=$ Arthritis Pain \\
Symptom & $=($ Social Activity + Support from Family and Friends $) \div 2$ \\
Social Interaction & $=$ Work \\
Role &
\end{tabular}

The data obtained from the AIMS2 questionnaire was analyzed using SPSS version 4.1 computer software. Frequencies, percentages, means, and standard deviations, where appropriate, were calculated to summarize all items. All scales and demographic questions were analyzed at pre-test for each of the two groups. The groups were compared on the demographic items using t-tests and Chi-Square tests, depending on the type of variable (i.e., age, t-test; gender, Chi-square).

To test the research hypotheses, t-tests for independent samples, pooled two sample procedures, were conducted on pre to post test differences between the experimental and comparison groups on each of the twelve scales of the AIMS2 (Mobility Level, Walking and Bending, Hand and Finger Function, Arm Function, Self-care, Household Tasks, Social Activities, Support from Family and Friends, Arthritis Pain, Work, Level of Tension, and Mood) and the additional items (Satisfaction with Function, Attribution of Problems to 
Arthritis, and Problem Prioritization). In addition, within group comparisons were carried out, using paired t-tests, on pre to post-test scale scores to look for improvements. For both groups, the scale changes from pre to post-test were ranked by size to see where most improvements were made. Ranking mean improvements were conducted for each group separately.

\section{Limitations of the Study}

Several limitations in this stidy affected the outcome. A small sample size and a short time frame in which to conduct the study made statistically significant findings due to the aquacize intervention difficult to achieve. Some variables were difficult to control; the majority of comparison group subjects were recruited in the fall of 1997, after completion of the experimental portion of the study.

Methods

The primary problems experienced with data collection were time constraints and use of convenience sampling methods. This study was planned to run during the spring and summer of 1997 when air and pool temperatures were optimal for persons with arthritis. Subjects were recruited for both groups at this time; the experimental group as they joined the AFAP classes, and the comparison from an organized senior activity group. However, most of the original comparison group failed to complete the post-test questionnaire for various reasons (length of questionnaire, vacations, illness, inability to contact participants). Therefore, additional comparison group participants were slowly recruited from various community sources over the fall and winter months. A differing period for questionnaire completion is an uncontrolled variable not accounted for, such as differences due to season (weather affecting arthritic pain, mood and level of tension due to stress over the holidays). 
Experimental subjects' prior participation in aquacize, although more than four months previous in all subjects, may have affected the results. Half of the second set of recruited comparison group participants were involved in a tap dance class, with regular practice sessions and performances before senior groups. They differed from the other five comparison group participants who stated they regularly exercised, but had no commitments to a particular type of exercise. This added another uncontrolled variable to the study. Recruiting comparison group members from one type of senior exercise group other than aquacize would have been preferable.

\section{$\underline{\text { Instrument }}$}

The length of the 78 item AIMS2 questionnaire was burdensome to the participants, leading to a low response rate. Because many subjects were unwilling to complete the posttest questionnaire, new participants had to be recruited over a longer span of time than originally intended for this study. Most of the comparison group participants completed the pre and post-test questionnaires at a later date than the experimental group.

Little reliability and validity information is currently available on shortened versions of the AIMS2. A shortened version might have allowed the researcher additional time for measurement of more variables. However, subtracting scale items would have affected reliability and validity of the original standardized measure.

Generalization of the results are limited because of the small sample size and convenience sampling method. Because only twenty women were involved in this study, not enough confidence can be placed in our conclusions about the differences between group means "because the precision of the comparison is primarily a function of the number of subjects in each group, not the reliability of the scale" (Daltry, 1997, p. 442). The larger the 
sample size, the smaller the confidence interval, and the greater the likelihood that an estimate is closer to the truth. Therefore results of this study cannot be generalized to similar populations. 


\section{CHAPTER IV}

Results

\section{Characteristics of Participants}

Two groups of women volunteered to complete AIMS2 questionnaires in a pretest/post-test design study. Nine women participated in the aquacize intervention for eight consecutive weeks, while eleven women acted as comparison group subjects.

A statistical analysis was performed to compare groups on demographic variables: age, gender, racial background, marital status, educational level completed, role, and economic status. Using t-tests for age and Chi-square $\left(\chi^{2}\right)$ tests for the remaining variables, no statistically significant differences were found between the two groups $(p<.05)$ on any of the demographic variables. See Table 2 for a breakdown of demographic data as reported on pre-test questionnaires. The mean age of the experimental group was 70.4 years $(S D=$ $7.9)$ and of the comparison was 73.6 years $(S D=6.5)$. All subjects reported a white-American racial background. All of the women had been married at one time, although five women in each group were currently widowed. Most subjects listed their work role as retired: $63 \%$ in the experimental group, $82 \%$ in the comparison. Although not significant, $67 \%$ of experimental subjects had a high school education or less, while $55 \%$ of the comparison group had some level of college education or greater. A total of 12 subjects answered the optional question regarding income: the majority of women in the experimental group (86\%) listed their family income as less than $\$ 20 \mathrm{~K}$ annually, while two subjects in the control group (40\%) reported family income greater than $\$ 60 \mathrm{~K}$. Since no significant differences were found between groups on demographic variables, it appears that the experimental and comparison groups were homogeneous. 
Table 2

Demographic Data for Subjects at Pre-test by Group

\begin{tabular}{|c|c|c|c|c|}
\hline Demographic Data & \multicolumn{2}{|c|}{ Experimental Group } & \multicolumn{2}{|c|}{ Comparison Group } \\
\hline $\begin{array}{l}\text { Total number of subjects }(\mathrm{N}) \\
\text { Age (years) } \\
\text { Mean } \\
\text { Standard Deviation } \\
\text { Range }\end{array}$ & \multicolumn{2}{|c|}{$\begin{array}{c}9 \\
\\
70.44 \\
7.86 \\
61-81\end{array}$} & \multicolumn{2}{|c|}{$\begin{array}{c}11 \\
73.55 \\
6.50 \\
66-86 \\
\end{array}$} \\
\hline Demographic Data & $\mathrm{n}$ & $\%$ & 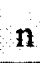 & $\%$ \\
\hline Female & 9 & 100.0 & 11 & 100.0 \\
\hline White-American & 9 & 100.0 & 11 & 100.0 \\
\hline Marital status & & & & \\
\hline Married & 3 & 33.3 & 5 & 45.5 \\
\hline Separated & 1 & 11.1 & 0 & 0.0 \\
\hline Divorced & 0 & 0.0 & 1 & 9.1 \\
\hline Widowed & 5 & 55.6 & 5 & 45.5 \\
\hline Highest education & & & & \\
\hline 7 th -11 th grade & 1 & 11.1 & 1 & 9.1 \\
\hline High school graduate & 5 & 55.6 & 4 & 36.4 \\
\hline $1-4$ years college & 1 & 11.1 & 2 & 18.2 \\
\hline College graduate & 0 & 0.0 & 2 & 18.2 \\
\hline Professional/post-graduate & 2 & 22.2 & 2 & 18.2 \\
\hline & & & & \\
\hline Housewife & 3 & 37.5 & 2 & 18.2 \\
\hline Retired & 5 & 62.5 & 9 & 81.8 \\
\hline Family income (optional) & & & & \\
\hline$<\$ 10,000$ & 1 & 14.3 & 1 & 20.0 \\
\hline $10-\$ 19,999$ & 5 & 71.4 & 1 & 20.0 \\
\hline $30-\$ 39,999$ & 1 & 14.3 & 1 & 20.0 \\
\hline$>\$ 60,000$ & 0 & 0.0 & 2 & 40.0 \\
\hline
\end{tabular}

Note. There were no statistically significant differences between the groups, $p<.05$, on any of the above demographic variables.

\section{Participants' General Medical Status at Pre-test}

The comparison group reported a mean number of years with arthritis of $17.8(S D=$ 15.1) while the experimental group reported a mean of 10.5 years $(S D=5.2)$, but the difference was not significant $(p=215)$. Both groups reported similar medication usage for their arthritis, ranging from "most to some days" (refer to Table 3). 
Table 3

General Medical Status of Subjects as Reported at Pre-test by Group

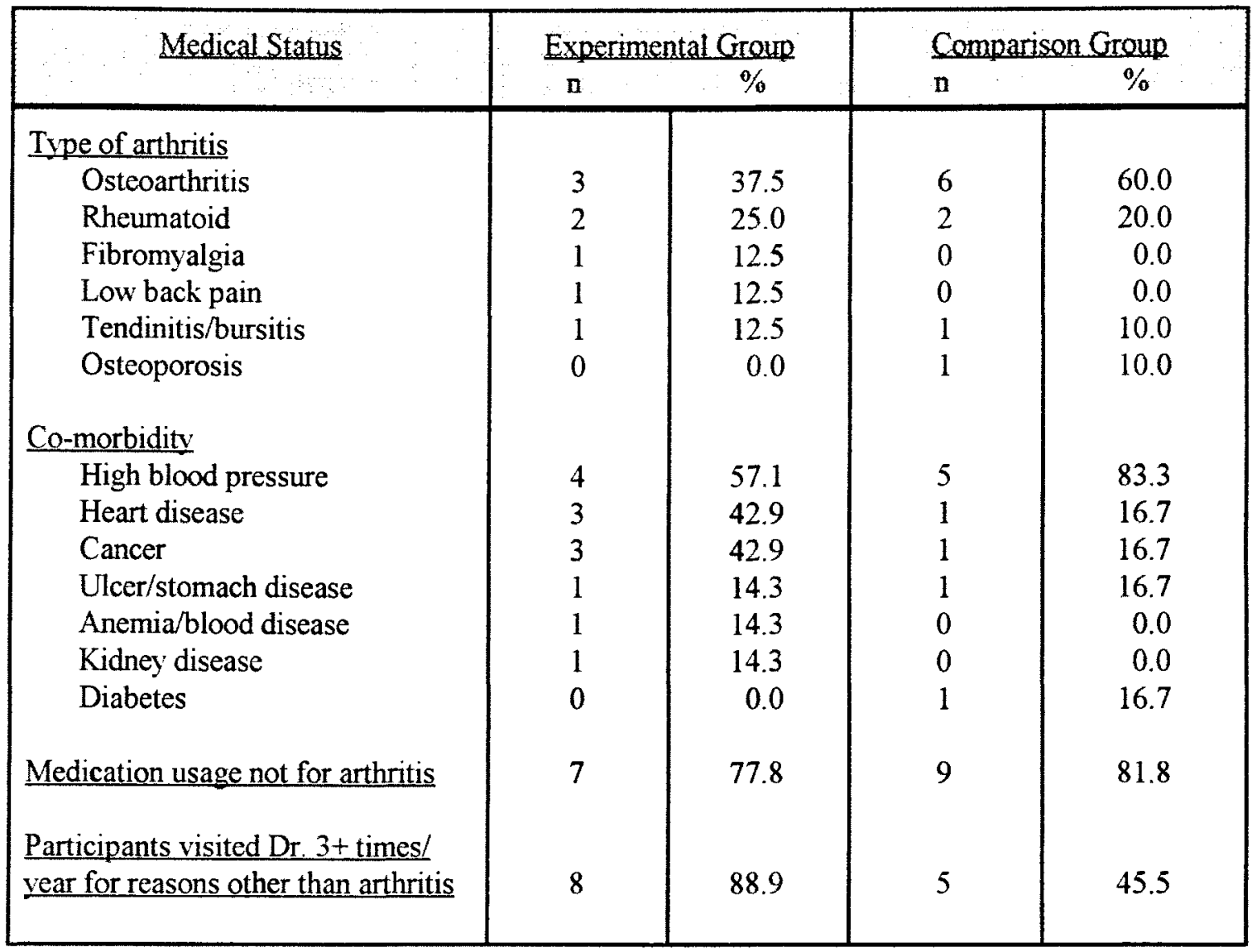

Cross tabulations using the Chi-square statistic were calculated to determine whether significant differences existed between the two groups on several AIMS2 questions referring to subjects' overall medical status. These questions included type of arthritis, non-arthritis medication usage, and comorbidity. No statistically significant differences $(p<.05)$ were found between the experimental and comparison groups on these questions at pre-test.

Though not all subjects reported their type of arthritis, osteoarthritis was ranked first by both groups as their main form, followed by rheumatoid arthritis. Other types reported are listed in Table 3, including fibromyalgia, and non-arthritic disorders such as low back pain, tendinitis, and osteoporosis. All participants considered their current health 
problems to be, at least in part, due to their arthritis.

When asked if their health was currently affected by other medical issues, the majority of subjects in both groups indicated problems with high blood pressure. Subjects in the experimental group also reported a higher frequency of heart disease and cancer (43\%) than the comparison group (17\%). As displayed in Table 3, the majority of subjects in both groups reported daily medication usage for problems other than arthritis. Although not significant; most of the experimental group (88.9\%) reported doctor visits greater than three times in the last year for reasons other than for arthritis, as compared to $45.5 \%$ of the comparison group. Since no statistically significant differences $(p<.05)$ were found on any of the above variables, one can assume that the two groups were homogeneous in their overall medical status at pre-test.

\section{Participants' Exercise Characteristics}

The principal investigator had added additional questions to the first page of the AIMS2 questionnaire booklet. This requested information was pertinent to determining subjects' eligibility for the study as well as ascertaining present and prior participation in therapeutic and rote exercise and aquacize exercise. These results are reported for descriptive purposes only and not to answer either research question. At pre-test, no statistically significant differences were found between the experimental and comparison group subjects when asked if they regularly participate in any form of exercise, and the number of hours they do so each week (see Table 4). Walking, bicycling, and dancing were listed by subjects in both groups as their main forms of exercise other than aquacize. Six of nine experimental group subjects were returnees to an Arthritis Foundation Aquatic Program (AFAP); 83\% had participated six months or more. Four comparison group subjects reported prior participation 
in some form of water exercise, however, none with an AFAP program. As expected, statistically significantly results, $\chi^{2}(1, N=20)=5.69, p=.017$, were obtained when compared with experimental subjects' prior participation in water exercise. Except for prior participation in water exercise, one can assume that the two groups were homogeneous in their overall exercise status at pre-test.

Table 4

Exercise Characteristics of Subjects by Group

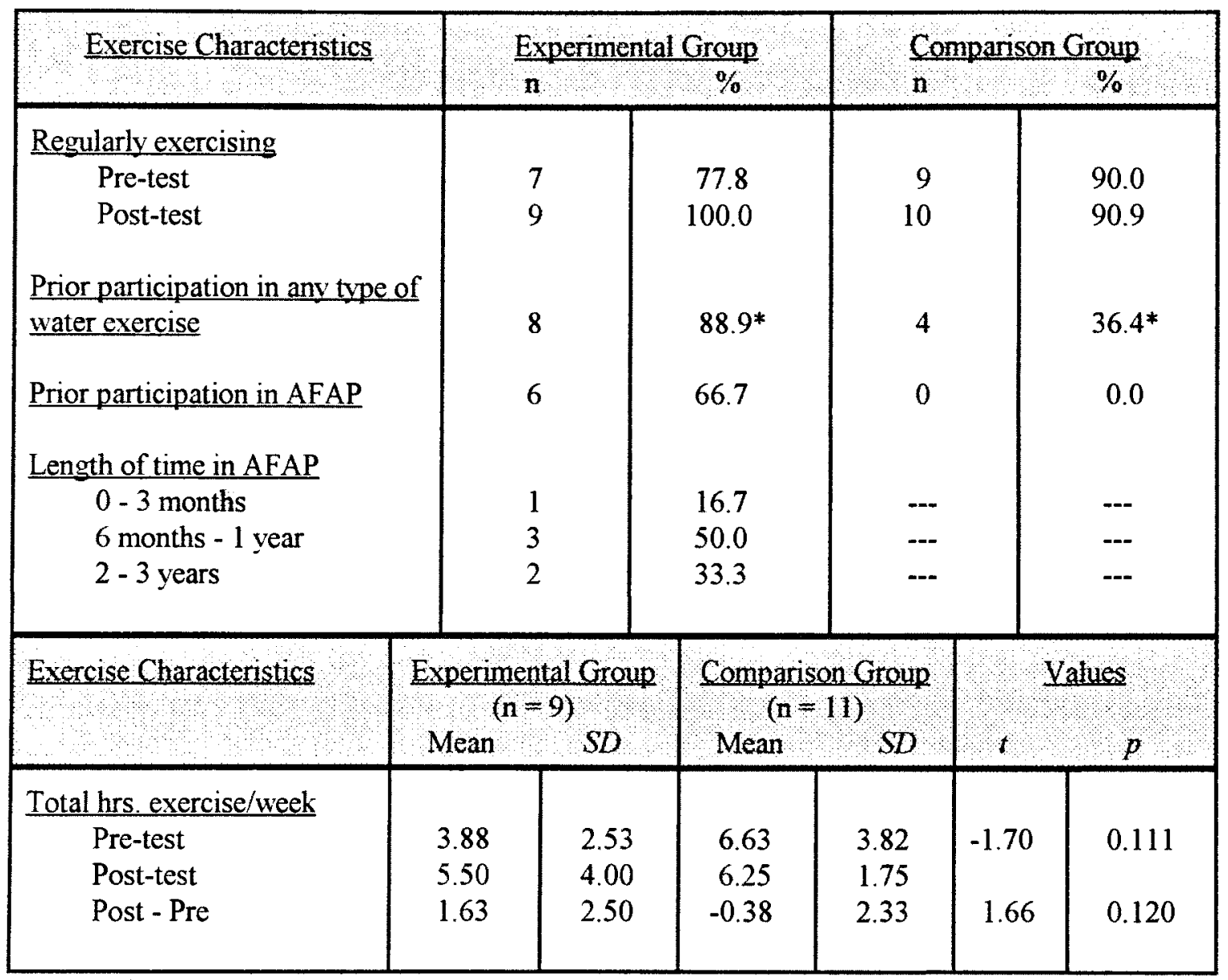

Note. Dashes indicate comparison group participants were not asked these questions.

${ }^{*} \chi^{2}(1, N=20)=5.69, p=0.017$. 
As expected, all members of the experimental group reported regular participation in exercise at post-test; the percentage of those in the comparison group still exercising remained the same. No statistically significant differences were found between the groups in regular participation in exercise, as well as in the mean change scores for total hours of weekly exercise. The experimental group reported increased number of exercise hours at post-test as compared to the comparison groups' half hour decline; however, this difference was not statistically significant $(p=.109)$.

\section{Scoring of AIMS2 Questionnaire}

The AIMS2 instrument was employed to measure health status in a multidimensional fashion using specific scales, summary components, and overall impact measures. All scoring was performed according to AIMS2 User's Guide (Meenan \& Mason, 1994).

Questions one through 57 were broken down into twelve scales/Health Areas: Mobility Level, Walking and Bending, Hand and Finger Function, Arm Function, Self-Care Tasks, Household Tasks, Social Activity, Support from Family and Friends, Arthritis Pain, Work, Level of Tension, and Mood. Each scale, comprised of four or five items/questions, was scored in a consistent fashion, with a low value indicating a high health status. To avoid systematic response bias, some response arrangements were mixed and then recoded in the proper direction prior to calculation. After recoding, the raw scores of every item within the scale were added together. A normalization procedure was then performed in order to express all scores in a range of $0-10$, with 0 representing good health status and 10 representing poor health status. Scalability, reliability, and validity of the scales were based upon the assumption that all items within the scale had been answered (Meenan \& Mason, 1994).

The authors of the AIMS2 (Meenan \& Mason, 1994) allow a scale score modification 
to adjust for the fact that health status problems in a particular area of function may be due to problems other than arthritis. Each AIMS2 scale score can be multiplied by differing factors based on subject's response to question 59, attributing problems with each area of health to arthritis. Adjusted values can be used when sample population age is reported as greater than 60 and comorbidity totals greater than two (refer to Tables 2 and 3 ). All subjects reported their age as older than 60 ; however, condition two was only partially met. Two of nine experimental subjects reported their health was affected by three differing medical problems; none of the comparison group reported a comorbidity greater than two. Therefore, this researcher opted not to utilize arthritis adjusted scores for the tests on the twelve scales.

Five statistical tests were performed on all variables: 1) pre-test and 2) post-test comparisons of categorical variables by group using cross tabulations and chi square statistics; 3) pre-test comparisons of numeric variables by group using t-tests for independent samples; 4) differences from pre to post by group using t-tests for independent samples; and 5) pre to post-test changes for each group separately using McNemar's Tests for categorical variables, and t-tests for paired samples on pre to post numeric scores (e.g., scale scores).

A five component model of arthritis adjusted health status was calculated using AIMS2 scale scores. The five general categories encompass the physical, affect, symptom, social, and work components. Meenan \& Mason (1994) require that individual scales within each component be normalized and adjusted prior to any component grouping. Thus, for this part of the analysis, the twelve scales were adjusted.

\section{Research Hypotheses}

The first research hypothesis states that regular participation in Arthritis Foundation sponsored aquacize classes would be effective in improving health status of older persons 
with arthritis. In order to test this hypothesis, within group comparisons were carried out using paired t-tests on pre to post-test scale score differences on each of the twelve scales of the AIMS2, as well as on the additional items, to look for improvements in the aquacize group. In addition, the same tests were performed on the comparison group.

The second research hypothesis states that older persons with arthritis, after regular participation in Arthritis Foundation sponsored aquacize classes, will report more improvements in health status than a comparison group also regularly engaged in various types of therapeutic and rote exercise. This hypothesis was tested by analyzing pre to post test differences between the experimental and comparison groups on each of the questions comprising the twelve scales of the AIMS2 and on the additional items using t-tests for independent samples.

\section{AIMS2 Items and Scales at Pre-Test}

To determine equivalence between groups at pre-test, t-tests for independent samples were performed on each question comprising the twelve AIMS2 scales and the additional items. Using unadjusted values, t-tests for independent samples were also performed on each of the twelve scales of the AIMS2 by groups (refer to Tables 5 and 6). Responses by participants to most AIMS2 questions comprising the twelve scales were presented as ability to perform tasks: 1 = "all days", 2 = "most days", 3 = "some days", $4=$ "few days", 5 = "no days". After normalization procedures were performed on each question's raw score, a literal interpretation of the results is not applicable. However, a general interpretation of the above stated numbering corresponds to a normalized score of: $1=0 ; 2=2.5 ; 3=5 ; 4=7.5$; and 5 $=10$. A normalized mean score of 0 signifies good health status, a higher mean score (10) indicates more problems with that area of health. 
Table 5

Normalized Test Results for Each of the 12 Unadjusted AIMS2 Scales by Group

\begin{tabular}{|c|c|c|c|c|c|c|}
\hline \multirow[t]{2}{*}{ AIMS2 Scales } & \multicolumn{2}{|c|}{ Experimental Group } & \multicolumn{2}{|c|}{ Comparison Group } & \multicolumn{2}{|c|}{ Values } \\
\hline & Mean & $S D$ & Mean & $S D$ & $t$ & $p$ \\
\hline Mobility (n) & (9) & & (11) & & & \\
\hline Pre-test & 3.06 & 2.80 & 0.95 & 1.04 & 2.31 & $0.033^{*}$ \\
\hline Post-test & 1.61 & 0.86 & 1.00 & 1.58 & & \\
\hline Pre - Post & $\begin{array}{c}1.44 \\
p=0.099\end{array}$ & 2.32 & -0.05 & 1.82 & 1.61 & 0.125 \\
\hline Walking \& bending ( $\mathrm{n}$ ) & (9) & & (11) & & & \\
\hline Pre-test & 5.33 & 2.77 & 3.41 & 2.23 & 1.72 & 0.102 \\
\hline Post-test & 5.06 & 2.60 & 3.23 & 2.34 & & \\
\hline Pre - Post & 0.28 & 2.85 & 0.18 & 2.34 & 0.08 & 0.935 \\
\hline Hand \& finger funct. (n) & (9) & & (11) & & & \\
\hline Pre-test & 1.33 & 1.23 & 1.73 & 1.69 & -0.58 & 0.567 \\
\hline Post-test & 1.61 & 1.60 & 1.27 & 1.49 & & \\
\hline Pre - Post & -0.28 & 0.87 & 0.45 & 1.15 & -1.57 & 0.133 \\
\hline Arm function ( $\mathrm{n}$ ) & (9) & & (11) & & & \\
\hline Pre-test & 2.06 & 2.23 & 1.23 & 2.14 & 0.85 & 0.409 \\
\hline Post-test & 1.56 & 1.79 & 1.86 & 2.93 & & \\
\hline Pre - Post & 0.50 & 0.94 & $\begin{array}{c}-0.64 \\
p=0.089\end{array}$ & 1.12 & 2.43 & $0.026^{*}$ \\
\hline Self-care tasks (n) & (9) & & (11) & & & \\
\hline Pre-test & 0.63 & 0.83 & 0.45 & 0.97 & 0.42 & 0.682 \\
\hline Post-test & 0.28 & 0.63 & 0.74 & 1.70 & & \\
\hline Pre - Post & $\begin{array}{c}0.35 \\
p=0.095\end{array}$ & 0.55 & -0.28 & 1.41 & 1.26 & 0.223 \\
\hline Household tasks (n) & (9) & & (11) & & & \\
\hline Pre-test & 1.32 & 1.45 & 0.34 & 0.58 & 2.06 & 0.054 \\
\hline Post-test & 0.94 & 0.95 & 1.08 & 1.51 & & \\
\hline Pre - Post & $\begin{array}{c}0.55 \\
p=0.064\end{array}$ & 0.70 & -0.74 & 1.53 & 2.20 & $0.042^{*}$ \\
\hline
\end{tabular}

Note. $*$ There is a statistically significant difference at the $5 \%$ level.

A higher mean score indicates more problems with that area of health; therefore, a positive change from pre to post test indicates an increase in ability. 
Table 6

Normalized Test Results for Each of the 12 Unadjusted AIMS2 Scales by Group (continued)

\begin{tabular}{|c|c|c|c|c|c|c|}
\hline \multirow[t]{2}{*}{ AIMS2 Scales } & \multicolumn{2}{|c|}{ Experimental Group } & \multicolumn{2}{|c|}{ Comparison Group } & \multicolumn{2}{|c|}{ Values } \\
\hline & Mean & $S D$ & Mean & $S D$ & $t$ & $p$ \\
\hline Social activity (n) & (9) & & (11) & & & \\
\hline Pre-test & 3.83 & 1.28 & 3.09 & 1.63 & 1.12 & 0.279 \\
\hline Post-test & 4.44 & 0.98 & 2.55 & 1.54 & & \\
\hline Pre - Post & -0.38 & 1.25 & 0.55 & 1.70 & 1.30 & 0.212 \\
\hline Family Support (n) & (9) & & (11) & & & \\
\hline Pre-test & 0.90 & 1.37 & 1.31 & 1.26 & -0.69 & 0.501 \\
\hline Post-test & 1.25 & 1.43 & 1.76 & 1.95 & & \\
\hline Pre - Post & -0.35 & 0.89 & -0.45 & 1.43 & 0.20 & 0.847 \\
\hline Arthritis Pain (n) & (9) & & (11) & & & \\
\hline Pre-test & 5.28 & 2.35 & 5.18 & 2.10 & 0.10 & 0.924 \\
\hline Post-test & 4.94 & 2.07 & 4.14 & 1.91 & & \\
\hline Pre - Post & 0.33 & 1.90 & 1.05 & 2.06 & -0.80 & 0.436 \\
\hline Work (n) & (3) & & (2) & & & \\
\hline Pre-test & 2.08 & 1.57 & 2.19 & 0.44 & $\cdots$ & --- \\
\hline Post-test & 1.56 & 1.79 & --- & --- & & \\
\hline Pre - Post & 0.50 & 0.94 & -- & --- & $-\cdots$ & -- \\
\hline Level of tension (n) & (9) & & $(10)$ & & & \\
\hline Pre-test & 3.39 & 1.39 & 3.30 & 1.77 & 0.12 & 0.905 \\
\hline Post-test & 3.39 & 1.90 & 4.20 & 1.65 & & \\
\hline Pre - Post & 0.00 & 1.71 & -0.90 & 1.76 & 1.13 & 0.276 \\
\hline Mood (n) & (9) & & (11) & & & \\
\hline Pre-test & 1.56 & 1.26 & 2.00 & 1.18 & -0.81 & 0.428 \\
\hline Post-test & 1.11 & 0.99 & 2.00 & 1.00 & & \\
\hline Pre - Post & 0.44 & 0.95 & 0.00 & 1.23 & 0.89 & 0.385 \\
\hline
\end{tabular}

Note. Dashes indicate insufficient responses were received.

A higher mean score indicates more problems with that area of health; therefore, a positive change from pre to post test indicates an increase in ability. 
A statistically significant difference $(p<.05)$ was found between the two groups at pre-test on one of the twelve unadjusted AIMS2 scales, Mobility Scale $(p=.033)$. The comparison group's mean score $(M=0.95, S D=1.04)$ indicates they felt able "all days" to drive, run errands, go out of the house without assistance, and not be in a bed or chair. The experimentals reported more difficulties with mobility performance than the comparisons; their higher mean score $(M=3.06, S D=2.80)$ indicates they felt able "most days".

The AIMS2 questionnaire directed participants to omit the Work Scale section if unemployed, disabled, or retired. Since $81.8 \%(n=9)$ of the comparison group and $62.5 \%$ $(n=5)$ of the experimental group reported their main form of work as retired, an insufficient number of responses were received on the five Work Scale questions.

\section{Within Group Differences}

Hypothesis one proposed that regular participation in Arthritis Foundation sponsored aquacize is effective in improving health status in older persons with arthritis. To test this research hypothesis, within group comparisons were made using paired t-tests on pre to posttest changes in scale scores to look for improvements within the aquacize group. No significant changes in responses to questions regarding general medical status were reported by either group from pre-test to post-test (refer to Table 3).

Experimental group. No statistically significant improvements were found (refer to Tables 5 and 6) on any of the unadjusted AIMS2 Scales for the experimental group from pre to post-test $(p<.05)$. However, numerous positive changes, indicating some increase in Health Status, were reported by the experimental group. Improvements were seen on eight of the twelve AIMS2 scales: Mobility, Walking \& Bending, Arm Function, Self-care Tasks, Household Tasks, Arthritis Pain, Work, and Mood. Level of Tension was unchanged. 
Of the 52 questions comprising the AIMS2 Scales (five Work Scale questions were omitted), 27 improvements were reported by the experimental group from pre to post, with 11 unchanged mean responses. Statistically significant improvements were found on two individual questions within the scales. On the Mobility Scale, significant improvement $(p=$ .030) was found in the experimental group's mean change score in reported ability to drive a car or use public transportation. At pre-test, the experimental group reported they felt able to drive "most" days $(M=2.33, S D=1.50)$. From pre to post-test, their reported driving abilities had improved $(M=1.11, S D=.33)$ to "most to all" days, with a positive mean change $(M=1.22, S D=1.39)$. On the Walking and Bending Scale, reported ability to do vigorous activities (running, lifting heavy objects, or participating in strenuous sports) showed statistically significant changes $(p=.033)$. At pre-test, the experimental group reported they could perform vigorous activities on "some days" $(M=4.38, S D=.74)$. By post-test, they had reported improved abilities $(M=3.88, S D=1.13)$ to "most to some days", with a positive mean change from pre to post $(M=.50, S D=.54)$.

Comparison group. No statistically significant improvements were found on any of the twelve unadjusted AIMS2 Scales for the comparison group (refer to Tables 5 and 6). Paired t-tests were used to calculate mean differences from pre to post-test on 52 of 57 questions comprising the twelve AIMS2 Scales (five Work Scale questions were omitted). It was found that responses on 13 questions were unchanged, while 27 negative changes were reported by the comparison group. More declines than improvements in perceived Health Status were reported by the comparison group members at completion of eight weeks. However, none of the tests indicated significant changes. 
The second research hypothesis proposes that after regular participation in AFAP aquacize participants will report more improvements in health status than a comparison group not participating in the exercise intervention. To test this hypothesis, independent sample ttests were used to determine if there was a difference between the two groups on each of the twelve AIMS2 scales from pre to post-test. Statistically significant differences $(p<.05)$ were found between the two groups from pre-test to post-test (refer to Tables 5 and 6) on two of the eleven unadjusted AIMS2 scales: Arm Function $(p=.026)$ and Household Tasks $(p=$ .042 ); and on several individual questions within the AIMS2 scales.

At pre-test, the experimental group participants felt able "most" days $(M=2.06, S D$ $=2.23$ ) to perform Arm Function abilities: wipe their mouth, don a pullover, comb or brush their hair, scratch their lower back, and reach overhead shelves. The comparisons reported less problems with these tasks than the experimentals, feeling able "most to all" days $(M=$ $1.23, S D=.33)$. From pre to post-test, the experimentals' mean change score $(M=.50, S D$ $=.94$ ) indicated they had improved in reported arm functioning, to a "most to all" days level of ability $(M=1.56, S D=1.79)$. This improvement contrasts with the comparisons decline in mean change score $(M=-.64, S D=1.12)$ indicating more problems with arm functions, to a "most to all" days level of ability $(M=1.86, S D=2.93)$.

In the Arm Function Scale, the experimental group's improvement from pre to post $(M=.44, S D=.73)$ with combing or brushing hair was significantly different $(p=.039)$ than the comparison group's decline $(M=-.09, S D=.30)$. At pre-test, the comparison group respondents reported they felt able to brush or comb their hair "most to all days" ( $M=1.45$, $S D=1.21)$. The experimental group reported slightly more difficulties with this task $(M=$ 
$1.67, S D=.87$ ), although they also reported "most to all days" ability. From pre to post-test, the experimental group reported improved ability in $(M=1.22, S D=.44)$ hair combing performance, while the comparison group reported more difficulty with this task $(M=1.55$, $S D=1.21)$

Significant differences were also found between groups in mean change scores in the Household Tasks Scale. At pre-test, the experimental group's mean score showed they were less able than the comparisons to accomplish grocery shopping, meal preparation, laundry, and housework without assistance; feeling able "very often to always" ( $M=1.32, S D=1.45)$. From pre to post-test, their mean change score $(M=.55, S D=.70)$ showed improvement in reported household task performance, generally to an "always" level of ability $(M=.94, S D$ $=.95$ ). The opposite situation occurred with the comparisons. Their pre-test scores indicated "always" ability to perform household tasks $(M=.34, S D=.58)$. Their mean change score $(M=-.74, S D=1.53)$ declined from pre to post to a "very often to always" level $(M=1.08$, $S D=1.51$ ). These changes indicate that the comparisons had more problems with that health status area than the experimentals from pre to post-test.

One question in the Household Tasks Scale contributed to this difference between groups from pre to post. All control group respondents $(n=11)$ reported at pre-test that they could generally "always" prepare their own meals without assistance $(M=1.00, S D=.00)$, as compared to the experimentals" "often to always" $(M=1.38, S D=.52)$. By post-test, all experimental group members $(n=8)$ reported they could "always" prepare their own meals $(M=1.00, S D=.00)$, while the comparisons felt able "often to always" $(M=1.18, S D=.41)$. The experimental group participants' increased ability $(M=.38, S D=.52)$ to prepare meals was significantly $(p=.017)$ different than the comparison group's declined ability $(M=-.18$, 
$S D=.41)$ to accomplish the same task from pre to post.

Responses to other questions within the remaining AIMS2 scales also contributed to significant differences between groups in mean change scores. The question pertaining to ability to drive a car or take public transportation (one of five Mobility Scale items) was found to be significantly different between groups from pre to post-test $(p=.029)$. No mean change $(M=.00, S D=.89)$ was seen in the control group's "most" to "all days" level of reported ability from pre-test $(M=1.27, S D=.47)$ to post-test $(M=1.27, S D=.65)$. The experimental group reported they were less able to drive than the comparisons at pre-test, feeling able "most" days $(M=2.33, S D=1.50)$. However, by post-test their abilities had improved to a level $(M=1.11, S D=.33)$ higher than the comparison group had originally reported, with an positive mean change from pre to post $(M=1.22, S D=1.39)$. In the SelfCare Tasks Scale, significant between group differences were seen in mean change scores ( $p$ $=.047)$ on the question regarding frequency of need for assistance getting dressed. Although both groups' mean scores indicated "almost never" to "never" needing assistance, the experimental group's slight improvement $(M=.22, S D=.44)$ from pre to post contrasted with the control group's slight decline in dressing ability $(M=-.18, S D=.41)$ during the eight week span.

Results from Additional AIMS2 Questions at Pre and Post-Test

Pre-test. Tables $7,8,9,10,11$, and 12 illustrate results from nine additional AIMS2 questions (numbers 58 through 66 ) referring to overall health status. As indicated in Table 7 (questions regarding current and future health) a significant difference was found between groups at pre-test when asked "how big a problem do you expect your arthritis to be 10 years from now?". Responses were coded as 1 = "no problem at all", 2 = "minor problem", $3=$ 
"moderate problem", 4 = "major problem". The comparison group subjects reported significantly greater $(p=.039)$ expectations of having "minor" $(M=3.00, S D=.63)$ problems with arthritis ten years in the future while the experimental group anticipated generally "none to minor" problems $(M=2.33, S D=.71)$.

The remaining additional questions on this table include: rating of present health (ranged from 1 = "excellent" to 4 = "poor"); satisfaction with present health (from 1 = "very satisfied" to 5 = "very dissatisfied"); attributing present health problems to arthritis ( 1 = "not a problem" to $5=$ "due entirely to my arthritis"); expectations of future health in ten years (from 1 = "excellent" to $4=$ "poor"); and comparing present functioning to other persons of similar age (from $1=$ "very well" to 5 = "very poorly"). Since no significant differences were found between groups on these additional variables, one can assume that the experimental and comparison group's answers were similar at pre-test.

Satisfaction with each of the twelve health scale areas (question number 58) is depicted in Tables 8 and 9. Satisfaction response levels $(1=$ very satisfied, $2=$ somewhat satisfied, 3 = neither satisfied nor dissatisfied) were similar for both groups at pre-test with a low variance of responses. No statistically significant differences were found between groups at pre-test on their satisfaction levels with each scale area.

Post-test. From pre to post-test, statistically significant differences were again found regarding expectations of future arthritis problems, both within groups and in between groups comparisons (Table 7). Looking at the two groups separately, we see a significant difference from pre to post within the experimental group $(p=.022)$, reporting expectations of more problems with arthritis in the future. The experimental group's negative mean change score 
Table 7

Additional AIMS2 Questions: Current and Future Health of Subjects by Group

\begin{tabular}{|c|c|c|c|c|c|c|}
\hline Additional Questions & $\frac{\text { Experim }}{\text { Mean }}$ & $\frac{\text { Group }}{S D}$ & $\frac{\text { Compar }}{\text { Mean }}$ & $\frac{\text { Group }}{S D}$ & & ues \\
\hline Rating of present health (n) & (8) & & (10) & & & \\
\hline Pre-test mean & 2.38 & 0.74 & 2.09 & 0.54 & 0.97 & 0.347 \\
\hline Post-test mean & 2.13 & 0.84 & 1.19 & 0.57 & & \\
\hline Pre - Post & 0.25 & 0.46 & 0.20 & 0.92 & 0.14 & 0.891 \\
\hline Satisfaction with & & & & & & \\
\hline present health (n) & (9) & & (10) & & & \\
\hline Pre-test mean & 2.44 & 1.42 & 2.40 & 0.84 & 0.16 & 0.875 \\
\hline Post-test mean & 2.56 & 1.01 & 2.30 & 1.34 & & \\
\hline Pre - Post & 0.11 & 1.45 & 1.00 & 1.29 & -0.34 & 0.741 \\
\hline Problem with present health & & & & & & \\
\hline due to arthritis (n) & (7) & & (9) & & & \\
\hline Pre-test & 3.00 & 0.58 & 3.44 & 1.01 & -0.60 & 0.875 \\
\hline Post-test & 3.14 & 0.90 & 3.33 & 0.50 & & \\
\hline Pre - Post & -0.14 & 0.90 & 0.11 & 0.93 & -0.55 & 0.591 \\
\hline Expect health to be & & & & & & \\
\hline in 10 years (n) & (9) & & (10) & & & \\
\hline Pre-test & 2.44 & 0.88 & 2.30 & 0.68 & 0.23 & 0.819 \\
\hline Post-test & 2.22 & 0.67 & 2.40 & 0.70 & & \\
\hline Pre - Post & 0.22 & 0.67 & -0.10 & 0.88 & 0.89 & 0.384 \\
\hline Expect arthritis problems & & & & & & \\
\hline in $10 \mathrm{vrs}(\mathrm{n})$ & (9) & & (9) & & & \\
\hline Pre-test & 2.33 & 0.71 & 3.00 & 0.63 & -2.22 & $0.039^{*}$ \\
\hline Post-test & 3.00 & 0.87 & 2.67 & 1.00 & & \\
\hline Pre - Post & -0.67 & 0.71 & 0.33 & 0.87 & -2.68 & $0.016^{*}$ \\
\hline Comparison with others & $p=0.022^{*}$ & & & & & \\
\hline same age (n) & (7) & & (10) & & & \\
\hline Pre-test & 1.86 & 0.69 & 1.70 & 0.82 & 0.41 & 0.686 \\
\hline Post-test & 1.29 & 0.49 & 1.60 & 0.84 & & \\
\hline Pre - Post & 0.57 & 0.79 & 0.10 & 0.32 & 1.72 & 0.105 \\
\hline
\end{tabular}

Note. ${ }^{*}$ There is a statistically significant difference at the $5 \%$ level.

A higher mean score indicates more reported problems with health. A positive change from pre to post test indicates an increase in health status. 
$(M=-.67, S D=.71)$ pre to post indicates a significant decline from generally "none to minor" expectations of future problems to "minor" expectations $(M=3.00, S D=.87)$. From pre to post, changes between groups were also significantly different $(p=.016)$. The experimental group reported greater expectations of problems with arthritis in the future, while the comparisons anticipated lesser $(M=.33, S D=.87)$, reporting generally "minor" problems $(M$ $=2.67, S D=1.00$ ) at post-test.

From pre to post-test, no significant differences were found between groups or in mean change scores on any of the remaining additional AIMS2 questions pertaining to current and future health.

Comparison subjects reported significant improvements from pre to post on question \#58: Satisfaction with Each Health Area (refer to Tables 8 and 9). One statistically significant $(p=.045)$ result was found at post-test in the comparison group's mean improvement $(M=$ $.70, S D=.95)$ in satisfaction with Household Tasks (Table 8) from "somewhat satisfied" $(M$ $=2.60, S D=1.43)$ to generally "very to somewhat satisfied" $(M=1.90, S D=1.29)$. No statistically significant differences were found between groups from pre to post-test on their satisfaction levels with any scale area.

Question 59 asked participants to indicate the impact of arthritis on each area of health. Responses (from "due entirely to other causes" to "due entirely to my arthritis") were combined to ascertain whether the activity within each scale area was a "problem" or was "not a problem" (Table 10). No statistically significant differences were found at pre-test or at post-test on any of the twelve health scale areas. Arthritis Pain, Household Tasks, and Walking and Bending were the three most frequently cited problem areas by the experimental group at both pre and post-tests. These three health scale areas (as well as Hand and Finger 
Table 8

Additional AIMS2 Question: Satisfaction with Function in Each Health Area by Group

\begin{tabular}{|c|c|c|c|c|c|c|}
\hline Aims2 Scales & \multicolumn{2}{|c|}{ Experimental Group } & \multicolumn{2}{|c|}{ Comparison Group } & \multicolumn{2}{|c|}{ Values } \\
\hline & Mean & $S D$ & Mean & $S D$ & $t$ & $p$ \\
\hline Mobility (n) & (9) & & (11) & & & \\
\hline Pre-test & 1.78 & 0.83 & 1.82 & 0.75 & -0.11 & 0.910 \\
\hline Post-test & 1.67 & 0.50 & 1.55 & 0.69 & & \\
\hline Pre - Post & 0.11 & 0.60 & 0.27 & 0.79 & -0.51 & 0.619 \\
\hline Walking \& bending (n) & (9) & & (11) & & & \\
\hline Pre-test & 2.56 & 0.88 & 2.36 & 1.03 & 0.44 & 0.663 \\
\hline Post-test & 2.33 & 1.00 & 2.00 & 1.18 & & \\
\hline Pre - Post & 0.22 & 0.67 & 0.36 & 0.81 & -0.42 & 0.68 \\
\hline Hand \& finger funct. (n) & (9) & & (11) & & & \\
\hline Pre-test & 1.78 & 0.83 & 2.09 & 0.83 & -0.84 & 0.413 \\
\hline Post-test & 1.89 & 1.36 & 1.91 & 0.83 & & \\
\hline Pre - Post & -0.11 & 1.05 & 0.18 & 0.41 & -0.85 & 0.405 \\
\hline Arm function (n) & (9) & & (9) & & & \\
\hline Pre-test & 1.56 & 0.73 & 1.67 & 0.71 & -0.93 & 0.363 \\
\hline Post-test & 1.33 & 0.50 & 1.33 & 0.71 & & \\
\hline Pre - Post & 0.22 & 0.83 & 0.33 & 0.87 & -0.28 & 0.785 \\
\hline Self-care tasks (n) & (9) & & (9) & & & \\
\hline Pre-test & 1.33 & 0.50 & 1.33 & 0.50 & -1.07 & 0.301 \\
\hline Post-test & 1.22 & 0.44 & 1.11 & 0.33 & & \\
\hline Pre - Post & 0.11 & 0.60 & 0.22 & 0.44 & -0.45 & 0.661 \\
\hline Household tasks (n) & $(9)$ & & $(10)$ & & & \\
\hline Pre-test & 2.56 & 0.73 & 2.60 & 1.43 & -0.08 & 0.934 \\
\hline Post-test & 2.33 & 1.00 & 1.90 & 1.29 & & \\
\hline Pre - Post & 0.22 & 0.67 & $\begin{array}{c}0.70 \\
p=0.045^{*}\end{array}$ & 0.95 & -1.26 & 0.226 \\
\hline
\end{tabular}

Note. ${ }^{*}$ The mean change from pre to post is statistically different than zero at the $5 \%$ level.

A higher mean score indicates less satisfaction with that area of health; therefore, a positive change from pre to post test indicates an increase in satisfaction. 
Table 9

Additional AIMS2 Question: Satisfaction with Each Health Area by Group (continued)

\begin{tabular}{|c|c|c|c|c|c|c|}
\hline \multirow[t]{2}{*}{ Aims2 Scales } & \multicolumn{2}{|c|}{ Experimental Group } & \multicolumn{2}{|c|}{ Comparison Group } & \multicolumn{2}{|c|}{ Values } \\
\hline & Mean & $S D$ & Mean & $S D$ & $t$ & $p$ \\
\hline Social activity (n) & (9) & & (11) & & & \\
\hline Pre-test & 1.89 & 0.78 & 1.73 & 0.79 & 0.46 & 0.652 \\
\hline Post-test & 1.56 & 0.73 & 1.55 & 1.04 & & \\
\hline Pre - Post & 0.33 & 0.87 & 0.18 & 0.60 & 0.46 & 0.651 \\
\hline Family Support (n) & (9) & & (11) & & & \\
\hline Pre-test & 1.56 & 0.73 & 1.36 & 0.51 & 0.70 & 0.495 \\
\hline Post-test & 1.44 & 0.73 & 1.55 & 0.93 & & \\
\hline Pre - Post & 0.11 & 1.05 & -0.18 & 1.08 & 0.61 & 0.549 \\
\hline Arthritis Pain (n) & (9) & & (11) & & & \\
\hline Pre-test & 3.22 & 1.09 & 2.55 & 1.21 & 1.30 & 0.211 \\
\hline Post-test & 2.67 & 1.23 & 2.64 & 1.12 & & \\
\hline Pre - Post & 0.56 & 2.13 & -0.09 & 1.70 & 0.76 & 0.459 \\
\hline Work (n) & $(7)$ & & (7) & & & \\
\hline Pre-test & 2.71 & 0.76 & 3.00 & 1.16 & -0.59 & 0.566 \\
\hline Post-test & 2.57 & 0.98 & 3.00 & 1.29 & & \\
\hline Pre - Post & 0.14 & 1.57 & 0.00 & 1.92 & 0.15 & 0.881 \\
\hline Level of tension (n) & (9) & & (11) & & & \\
\hline Pre-test & 2.89 & 1.27 & 2.45 & 0.93 & 0.88 & 0.389 \\
\hline Post-test & 2.33 & 1.12 & 2.27 & 1.19 & & \\
\hline Pre - Post & 0.56 & 2.01 & 0.18 & 1.72 & 0.45 & 0.66 \\
\hline Mood (n) & (8) & & (11) & & & \\
\hline Pre-test & 2.50 & 1.77 & 3.00 & 1.27 & -0.72 & 0.481 \\
\hline Post-test & 2.25 & 1.75 & 2.45 & 0.93 & & \\
\hline Pre - Post & 0.25 & 1.75 & 0.55 & 1.64 & -0.38 & 0.710 \\
\hline
\end{tabular}

Note. A higher mean score indicates less satisfaction with that area of health; therefore, a positive change from pre to post test indicates an increase in satisfaction. 
Function) were also most frequently reported by the comparisons at post-test; however, Work rather than Walking and Bending was chosen more often at pre-test. No statistically significant differences were found between groups at pre-test or at post-test in each area of health.

Table 10

Additional AIMS2 Question: Arthritis Impact on Each Area of Health by Group: Activity within Each Scale Area Was a Problem

\begin{tabular}{|c|c|c|c|c|c|c|c|c|}
\hline \multirow{3}{*}{ AIMS2 Scales } & \multicolumn{4}{|c|}{$\frac{\text { Experimental Group }}{(n-9)}$} & \multicolumn{4}{|c|}{$\frac{\text { Comparison Group }}{(n=11)}$} \\
\hline & \multicolumn{2}{|c|}{ Pre } & \multicolumn{2}{|c|}{ Post } & \multicolumn{2}{|c|}{ Pre } & \multicolumn{2}{|c|}{ Post: } \\
\hline & $\mathbf{n}$ & $\%$ & $\mathbf{n}$ & $\%$ & $\mathbf{n}$ & $\%$ & $\mathbf{n}$ & $\%$ \\
\hline Mobility Level & 4 & 50.0 & 6 & 66.7 & 4 & 44.4 & 4 & 36.4 \\
\hline Walking \& Bending & 7 & 77.8 & 7 & 87.5 & 6 & 66.7 & 6 & 54.5 \\
\hline Hand \& Finger Function & 6 & 66.7 & 5 & 55.6 & 6 & 60.0 & 5 & 50.0 \\
\hline Arm Function & 3 & 33.3 & 3 & 33.3 & 6 & 66.7 & 4 & 36.4 \\
\hline Self-care & 0 & 0.0 & 2 & 22.2 & 4 & 40.0 & 4 & 36.4 \\
\hline Household Tasks & 8 & 88.9 & 6 & 75.0 & 8 & 88.9 & 5 & 50.0 \\
\hline Social Activities & 3 & 33.3 & 3 & 33.3 & 5 & 50.0 & 3 & 27.3 \\
\hline Support from Family & 1 & 12.5 & 3 & 37.5 & 4 & 44.4 & 2 & 20.0 \\
\hline Arthritis Pain & 9 & 100.0 & 8 & 88.9 & 8 & 80.0 & 10 & 90.9 \\
\hline Work & 3 & 50.0 & 5 & 62.5 & 7 & 77.8 & 4 & 57.1 \\
\hline Tension Level & 6 & 66.7 & 6 & 66.7 & 5 & 50.0 & 4 & 36.4 \\
\hline Mood & 5 & 62.5 & 4 & 44.4 & 5 & 50.0 & 4 & 36.4 \\
\hline
\end{tabular}

In question 60 (Table 11), participants chose three different health areas in which they would most like to see improvement. The experimental group's three most frequent choices at pre-test were the same as the three most frequently reported problem areas seen in Table 10: Arthritis Pain (67\%), Walking and Bending (44\%), and Household Tasks (44\%). The comparison group chose Hand \& Finger Function (55\%), as well as the three mentioned 
above: Arthritis Pain (82\%), Walking \& Bending (46\%), and Household Tasks (46\%). At post-test, the experimental group's percentages had changed slightly; Arthritis Pain (67\%), Walking \& Bending (67\%), and Hand \& Finger Function (44\%) more closely resembled the comparison group's responses at pre-test. The comparison group opted for the same four Health Scale Areas, though their percentages altered slightly from pre to post. At pre-test, they reported: Arthritis Pain (90\%), Household Tasks (50\%), Walking \& Bending (40\%), and Hand \& Finger Function (40\%); the same four choices as their most frequently reported problem areas at post-test (Table 10). No statistically significant differences were found between the groups at pre or post test on this question.

Table 11

Additional AIMS2 Question: Areas of Health Most Like to See Improvement by Group

\begin{tabular}{|c|c|c|c|c|c|c|c|c|}
\hline \multirow[b]{2}{*}{ AIMS2 Scales } & \multicolumn{4}{|c|}{$\frac{\text { Experimental Group }}{(n=9)}$} & \multicolumn{4}{|c|}{$\begin{array}{c}\text { Comparison Group } \\
(\mathrm{n}=11)\end{array}$} \\
\hline & n & $\mathrm{Pre}_{\%}$ & n & $\%$ & $\mathrm{n}$ & $\%$ & n & $\%$ \\
\hline Mobility Level & 2 & 22.2 & 3 & 33.3 & 0 & 0.0 & 0 & 0.0 \\
\hline Walking \& Bending & 4 & 44.4 & 6 & 66.7 & 5 & 45.5 & 4 & 40.0 \\
\hline Hand \& Finger Function & 2 & 22.2 & 4 & 44.4 & 6 & 54.5 & 4 & 40.0 \\
\hline Arm Function & 3 & 33.3 & 1 & 11.1 & 3 & 27.3 & 2 & 20.0 \\
\hline Self-care & 0 & 0.0 & 0 & 0.0 & 0 & 0.0 & 0 & 0.0 \\
\hline Household Tasks & 4 & 44.4 & 3 & 33.3 & 5 & 45.5 & 5 & 50.0 \\
\hline Social Activities & 1 & 11.1 & 2 & 22.2 & 0 & 0.0 & 0 & 0.0 \\
\hline Support from Family & 0 & 0.0 & 1 & 11.1 & 0 & 0.0 & 0 & 0.0 \\
\hline Arthritis Pain & 6 & 66.7 & 6 & 66.7 & 9 & 81.8 & 9 & 90.0 \\
\hline Work & 0 & 0.0 & 0 & 0.0 & 0 & 0.0 & 0 & 0.0 \\
\hline Tension Level & 3 & 33.3 & 0 & 0.0 & 3 & 27.3 & 2 & 20.0 \\
\hline Mood & 1 & 11.1 & 1 & 11.1 & 1 & 9.1 & 1 & 10.0 \\
\hline
\end{tabular}


Normalization procedures were performed on raw scores from questions 58,61 , and 66 as specified by AIMS2 User's Guide (Meenan \& Mason, 1994). These results are summarized in Table 12. A normalization procedure was applied to the raw scores with responses converted to a ten point scale. Question 58 asks for respondent satisfaction with each of the twelve Health Status Scales. Similar "somewhat satisfied" results were obtained from both groups regarding their satisfaction level $(M=2.81$ for both). Question 61 asks the respondent to rate her current health (health perceptions) on a scale from poor (4) to excellent (1) with a higher mean score indicating more problems. The experimental subjects rated their general health as "fair to good", while the comparisons' mean score indicated "good". Question 66 estimates the overall impact of arthritis, asking the respondent to compare her functioning with other persons of the same age. Both groups generally reported "very well to well". There was no significant differences between groups at pre-test or from pre to posttest on any of these normalized questions.

Table 12

Additional AIMS2 Questions by Group: Normalized

\begin{tabular}{|c|c|c|c|c|c|c|}
\hline Normalized Questions & \multicolumn{2}{|c|}{$\frac{\text { Expermental Group }}{\text { Mean }}$} & \multicolumn{2}{|c|}{ Comparison Group } & \multicolumn{2}{|c|}{ Vahues } \\
\hline Functional Satisfaction (n) & (9) & & (11) & & & \\
\hline Pre-test & 2.81 & 0.95 & 2.81 & 1.60 & 0.00 & 0.997 \\
\hline Post-test & 2.28 & 1.25 & 2.09 & 1.45 & & \\
\hline Pre - Post & 0.53 & 1.41 & 0.72 & 1.50 & -0.29 & 0.777 \\
\hline Health perceptions (n) & (8) & & (10) & & & \\
\hline Pre-test & 4.59 & 2.49 & 3.64 & 1.80 & 0.97 & 0.347 \\
\hline Post-test & 3.76 & 2.79 & 3.01 & 1.90 & & \\
\hline Pre - Post & 0.84 & 1.55 & 0.67 & 3.07 & 0.14 & 0.891 \\
\hline Arthritis impact (n) & ( 7$)$ & & (10) & & & \\
\hline Pre-test & 2.15 & 1.73 & 1.76 & 2.07 & 0.41 & 0.686 \\
\hline Post-test & 0.71 & 1.22 & 1.50 & 2.11 & & \\
\hline Pre - Post & 1.44 & 1.97 & 0.26 & 0.79 & 1.72 & 0.105 \\
\hline
\end{tabular}

Note. A higher mean score indicates more problems with that area of health. 
As mentioned previously in this chapter, a five component model of health status was calculated using normalized and adjusted values. Factor analyses (refer to chapter two) have shown that the original nine AIMS scales could be combined into three or five component models of health status through grouping specific scales. The authors of the AIMS2, Meenan \& Mason (1994), recommended the following component groupings: physical (mobility level, walking and bending, hand and finger function, arm function, selfcare tasks, household tasks); affect (level of tension, mood); symptom (arthritis pain); social interaction (social activity, support from family and friends); and role (work).

Component grouping results are depicted in Table 13. No significant differences were found between the experimental and comparison groups at pre-test in the Physical, Affect, Symptom, and Social Components. The Role Component was not calculated since an insufficient number of responses were received on questions comprising the work scale, as previously mentioned. The experimental group's mean change score from pre to posttest indicated a significant improvement $(p=.023)$ in the physical component while the comparison group did not change. No other changes from pre to post were noted for either experimental or comparison group.

\section{Ranking of Mean Scores and Changes From Pre to Post Test}

Refer to Table 14 for ranking, in order from most to least, reported problems within each AIMS2 Health Scale area based on mean scores at both pre and post-tests (refer to Tables 5 and 6 for means). A higher calculated mean score for each scale area indicated more problems with that health status area. The top four problem areas indicated by the experimental group at pre-test remained the same at post-test, in the same order of 
Table 13

Five AIMS2 Components by Group (Using Unadjusted Values)

\begin{tabular}{|c|c|c|c|c|c|c|}
\hline AIMS2 Components & $\frac{\text { Experim }}{\text { Mean }}$ & $\frac{\text { Group }}{S D}$ & $\frac{\text { Compa }}{\text { Mean }}$ & $\frac{\text { Sroup }}{S D}$ & $t$ & ues \\
\hline Physical (n) & (9) & & (10) & & & \\
\hline Pre-test & 2.29 & 1.26 & 1.35 & 0.98 & 1.08 & 0.295 \\
\hline Post-test & 1.83 & 0.85 & 1.53 & 1.23 & & \\
\hline Pre - Post & $\begin{array}{c}0.46 \\
p=0.023 *\end{array}$ & 0.49 & -0.18 & 0.92 & 1.87 & $0.079+$ \\
\hline Affect (n) & (9) & & (10) & & & \\
\hline Pre-test & 2.47 & 1.18 & 2.59 & 1.28 & 0.23 & 0.821 \\
\hline Post-test & 2.25 & 1.36 & 3.02 & 1.20 & & \\
\hline Pre - Post & 0.22 & 1.10 & -0.43 & 1.36 & 1.17 & 0.259 \\
\hline Symptom (n) & (9) & & (10) & & & \\
\hline Pre-test & 5.28 & 2.35 & 5.18 & 2.10 & 0.95 & 0.354 \\
\hline Post-test & 4.94 & 2.07 & 4.14 & 1.91 & & \\
\hline Pre - Post & 0.33 & 1.90 & 1.05 & 2.06 & -0.80 & 0.436 \\
\hline Social (n) & (9) & & (10) & & & \\
\hline Pre-test & 2.37 & 1.11 & 2.20 & 1.30 & 0.99 & 0.335 \\
\hline Post-test & 2.60 & 1.33 & 2.15 & 1.56 & & \\
\hline Pre - Post & -0.23 & 0.63 & 0.05 & 1.12 & -0.65 & 0.522 \\
\hline \multirow[t]{2}{*}{ Work (n) } & (1) & & (2) & & & \\
\hline & -- & -- & $-\cdots$ & --- & --- & -- \\
\hline
\end{tabular}

Note: Dashes indicate insufficient responses were received to calculate the Work Component.

* The mean change from pre to post is statistically different than zero at the $5 \%$ level.

+ The mean change from pre to post is statistically different than zero at the $10 \%$ level.

functional difficulty. The comparison groups' top four problems areas at pre-test were the same as the experimental group's, although they were ranked in different order of difficulty. Again, at post-test, the comparison group's top four problem areas remained the same, but differed from their rankings at pre-test. 
Ranking of Scales Indicating Most to Least Problems With Each Scale Area by Group

\begin{tabular}{|l|l|l|l|}
\hline \multicolumn{2}{|c|}{ Experimental Group } & \multicolumn{2}{c|}{ Comparison Group } \\
\hline \multicolumn{1}{|c|}{ Pre-Test } & \multicolumn{1}{|c|}{ Post-Test } & \multicolumn{1}{|c|}{ Pre-Test } & \multicolumn{1}{c|}{ Post-Test } \\
\hline 1. Walking \& & 1. Walking \& & 1. Arthritis Pain & 1. Level of \\
Bending & Bending & 2. Walking \& & Tension \\
2. Arthritis Pain & 2. Arthritis Pain & Bending & 2. Arthritis Pain \\
3. Social Activity & 3. Social Activity & 3. Level of & 3. Walking \& \\
4. Level of & 4. Level of & Tension & Bending \\
Tension & Tension & 4. Social Activity & 4. Social Activity \\
5. Mobility & 5. Mobility/ & 5. Work & 5. Mood \\
6. Work & Hand \& Finger & 6. Mood & 6. Arm Function \\
7. Arm Function & Function* & 7. Hand \& Finger & 7. Household \\
8. Mood & 6. Arm Function/ & Function & Tasks \\
9. Hand \& Finger & Work* & 8. Family Support & 8. Family Support \\
Function & 7. Family Support & 9. Arm Function & 9. Hand \& Finger \\
10. Household & 8. Mood & 10. Mobility & Function \\
Tasks & 9. Household & 11. Self-Care Tasks & 10. Mobility \\
11. Family Support & Tasks & 12. Household & 11. Self-Care Tasks \\
12. Self-Care Tasks & 10. Self-Care Tasks & Tasks & \\
\hline
\end{tabular}

Note. Not sufficient responses received from comparison group to calculate Work Scale at post-test.

* Duplicate mean scores were obtained in these Scale areas.

Ranking of mean scale changes from pre to post-test by group indicates where most improvements were made. Table 15 ranks the twelve AIMS2 Health Scale Areas in order from most to least mean improvements by group based on mean scores at both pre and posttests (refer to Tables 5 and 6 for means). The experimental group showed seven areas of improvement (two statistically significant) as compared to four areas for the control group. No mean change was found in one area for both groups from pre to post test. The experimental group showed a mean decline in health status from pre to post-test in three areas (as ranked in order from most to least negative mean scale change), while the comparison group showed a decline in six of the eleven calculated AIMS2 Health Scale areas. 
Table 15

Mean Changes in Health Status: Ranked in Order from Most to Least Improved by Group

\begin{tabular}{|c|c|c|}
\hline Changes & Experimental Group & Comparison Group \\
\hline Improved: & $\begin{array}{l}\text { Mobility } \\
\text { Household Tasks* } \\
\text { Arm Function*/Work } \\
\text { Mood } \\
\text { Self-Care Tasks } \\
\text { Arthritis Pain } \\
\text { Walking and Bending }\end{array}$ & $\begin{array}{l}\text { Arthritis Pain } \\
\text { Social Activity } \\
\text { Hand and Finger Function } \\
\text { Walking and Bending }\end{array}$ \\
\hline No Change: & Level of Tension & Mood \\
\hline Declined: & $\begin{array}{l}\text { Social Activity } \\
\text { Family Support } \\
\text { Hand and Finger Function }\end{array}$ & $\begin{array}{l}\text { Level of Tension } \\
\text { Household Tasks } \\
\text { Arm Function } \\
\text { Family Support } \\
\text { Self-Care Tasks } \\
\text { Mobility }\end{array}$ \\
\hline
\end{tabular}

Note. ${ }^{*}$ Statistically significant improvements $p<.05$.

\section{Summary}

In conclusion, the experimental and comparison group participants were shown to be homogeneous at pre-test: demographically, in general medical status, in exercise characteristics, and in mean responses on ten of eleven computed AIMS2 health status scale areas. Significant differences between groups were found in the Mobility Scale at pre-test ( $p$ $=.033$ ), and on the additional question pertaining to expectations of problems with arthritis in the future $(p=.039)$.

In testing for pre to post-test changes for each group separately, no significant changes were seen on the twelve AIMS2 scales for either group. The experimental group significantly reported greater expectations of problems with arthritis in the future from pre to post-test on an additional question $(p=.022)$. Significant changes were reported by the comparison group on another additional question, showing improved satisfaction with 
Household Tasks $(p=.045)$. When the six scale areas (Mobility, Walking and Bending, Hand/Finger and Arm Function, Self-care and Household Tasks) were combined to create the Physical Component, the experimental group showed a statistically significant improvement in health status $(p=.023)$. Therefore, there is some evidence to accept the first research hypothesis: that regular participation in Arthritis Foundation sponsored aquacize classes will be effective in improving health status of older persons with arthritis.

A significant difference between groups from pre to post-test was seen in expectations of problems with arthritis in the future $(p=.016)$. The experimental group participants felt they would encounter more problems in the future, while the comparison group respondents anticipated less, from pre to post-test. Statistically significant differences were also found to exist between the two groups from pre to post-test in two of the eleven tested health scale areas: Arm Function $(p=.026)$ and Household Tasks $(p=.042)$. The experimental group reported improvements in both of these areas while the comparisons reported declines. Therefore, some evidence was provided to accept the second research hypothesis: that older persons with arthritis, after regular participation in Arthritis Foundation sponsored aquacize classes, will report more improvements in health status than a comparison group also regularly engaged in various types of therapeutic exercise. 


\section{CHAPTER V}

\section{Discussion}

\section{Relationship to Conceptual Framework}

The Person-Environment-Performance Framework (Christensen, 1991) was used as the conceptual framework for this study. It was theorized that: as an open system, transaction or interplay occurs between individuals and their environment, each influencing the other in a reciprocal manner. Performance is altered in a dynamic fashion based on subjective judgments of changing environmental conditions and self perceptions of the meaning of those changes as they relate to well-being.

The opinion of this researcher is that the AFAP aquacize participants improved because of interaction with and influence of their environment. This environment consisted of a cohort of other women of similar age with similar problems meeting twice a week in a fun, stimulating, supportive, social situation. The women interacted socially: often talking to each other throughout the session; a "pot-luck luncheon" was held once monthly to which all prepared and shared food; sometimes participants met for other activities after class. This environment consisted of multiple sensory stimulations: beautiful pool surroundings, colorful bathing suits, warm water, music from the forties, smells and tastes of food served at the luncheons. The environment also consisted of physical interactions with the water in active movement, creating feelings of increased flexibility and buoyancy achieved due to the physical properties of water. These interactions with the environment stimulated the mind and body and facilitated changed perceptions of self and encouraged feelings of well-being.

For the women participating in AFAP aquacize, performance was altered dynamically as evidenced by reported improvements in physical functioning within their environment. The 
AIMS2 assessed the multi-dimensional aspect of health, using indices of physical health combined with measures of social and psychological well-being. The five component model of health status measured these domains (Meenan \& Mason, 1994). The nine AFAP exercisers showed improvements (Table 15) in five of the six scale areas of the AIMS2 Physical Component (Mobility Level, Walking and Bending, Arm Function, Self-care, and Household Tasks). Although separately their reported improvements in each of these areas from pre to post were not found to be significant, a significant improvement in the Physical Component (Table 13) resulted when the mean change scores were combined. Only in Hand and Finger Function was there a non-significant decline.

These findings may be due to the instructor's emphasis on certain types of exercise. The AFAP aquacize protocol specifies exercises for all major muscle groups (AF \& YMCA, 1990). Their manual states a well rounded program should include at least one exercise from each category: walking, trunk stretching, shoulders, elbows, wrists and fingers, breathing and chest expansion, hips and knees, ankles and toes, and lower extremity and abdominal area. The instructor tended to focus her hour long sessions on larger gross motor movements in the water, with only ten repetitions of wrist and finger flexion/ extension exercises typically performed during cool-down.

An interplay exists between self perceptions of a dynamically changing environment and performance. "Self-reported measures of function are reflections of the levels at which patients believe they are able to perform" (Abdel-Moty et al., 1996, p. 19). People report higher levels of performance when they perceive themselves as able. Burckhardt et al.'s (1994) study of 99 Swedish women, as well as Lomi et al.'s (1995) follow-up article, reported improved health status and increased belief in abilities to accomplish specific tasks 
in physical functioning (improved self-efficacy) in those receiving water exercise and education regarding their disorder. Burckhardt et al. reported strong evidence to support the theory that changes in self-efficacy affect changes in health behaviors and health status, adding support to the theory that self perceptions of the meaning of change have an influence on health.

The same self-report measure (AIMS2) was used in this research study to compare participants' perceptions of functional ability prior to the intervention, and at completion of eight weeks of water exercise. Improved self-efficacy may explain why the aquacizers reported improvements over this time while the comparisons declined. From pre to post-test, the women who participated in AFAP aquacize significantly reported increased abilities in performance of Arm Function and Household Tasks (Table 5); as compared to the other group of women, also regularly exercising, who reported a decline in function in these areas. Although the comparisons reported significantly more satisfaction with housework from pre to post (Table 8), this didn't necessarily translate into their feeling more able to perform Household Tasks. It was the AFAP aquacizers who showed significantly more improvement in this area as compared to the comparisons' decline from pre to post-test. It is possible that their improved self-efficacy, a variable not measured in this study, contributed to these findings.

Subjective judgments of changing environmental conditions and self perceptions of the meaning of those changes as they relate to well-being may have also influenced results on one of the additional questions. From pre to post-test, the experimental group participants reported significantly greater expectations that their arthritis would create problems in the future. Exposure to persons with varying levels of ability due to their disorder is one of the 
negative aspects of therapeutic group experiences. Mobility is the one area in which the experimental and comparison groups were found to be significantly different at pre-test (refer to Table $5, p=.033$ ). The aquacizers reported more difficulties with mobility performance than the comparisons, having trouble with walking and bending "all days". The AFAP aquacizers were a visibly heterogenous mixture of women, ages ranged from 61 to 81 , with obvious differing mobility capabilities. Several aquacizers needed walkers or canes as assistive devices for mobility; frequently requiring contact guard assistance while negotiating pool steps, both entering and leaving. It is possible that exposure to these visible differences during the eight week pre to post-test period affected the aquacizers' responses, resulting in reports of increased expectations of future problems with arthritis.

\section{Relationship to Literature}

Respondent's demographic characteristics (refer to Table 2) are similar to those reported in two published articles (Meyer \& Hawley, 1994; Tork \& Douglas, 1989) involving AFAP participants. All three studies found the majority of respondents to be: Caucasian, female, over the age of 65 , and retired (Table 2). Tork \& Douglas reported that $63 \%$ of AFAP participants had osteoarthritis; identical to this research study's percentage (Table 3) if low back pain, tendinitis, and bursitis were combined with osteoarthritis (feasible, because many participants were not sure of their diagnosed form of arthritis). Subjects' length of time exercising with an AFAP program are also similar (refer to Table 4); $30 \%$ of Tork and Douglas's subjects reported duration of more than two years, comparable to $33 \%$ in this study.

AFAP aquacizers' characteristics in demographics and in psychological well-being at pre-test are similar to those of the AFAP participants' in Meyer and Hawley's (1994) 
study. These researchers compared 87 participants attending community-based water exercises to 174 disease, age, and sex matched patients attending an arthritis disease clinic. They found that those attending the clinic differed significantly $(p<.01)$ from the pool exercisers' scores on the anxiety $(M=2.80, S D=1.49)$ and depression $(M=1.80, S D=1.04)$ scales of the original AIMS. The water exercisers' scores indicated lesser severity of problems with these areas as compared to persons attending the arthritis clinic. The AFAP participants' mean scores obtained in Meyer and Hawley's study are similar to this study's AFAP aquacizers' in the Affect Component at pre-test (refer to Table $12 ; M=2.47, S D=1.18$ ).

Tork and Douglas reported results from a self-assessment survey sent to 600 Kansas AFAP participants evaluating program effectiveness. Their non-standardized questionnaire asked respondents to rate perceived improvements due to water exercise using three general categories: joint flexibility, muscle strength, and activities of daily living. Respondents ( $\mathrm{n}=$ 201) reported improvements in these areas due to participation in AFAP, with scores on the "improved" end of a five point scale. Findings of statistically significant improvements on two Physical Component scales (Arm Function, Household Tasks) in this research study are similar to those of Tork and Douglas's survey findings. The current study's use of a quasiexperimental two group pre- post test research design contributes to further knowledge of AFAP program effectiveness.

Reported functional improvements are in agreement with two other studies. Several arthritis patients in Danneskiold-Samson et al.'s (1987) non- controlled study $(n=8)$ reported a higher degree of abilities in performance of activities of daily living and more freedom to move after bi-weekly water exercise sessions for two months. Hansen et al. (1993) found no statistically significant differences between five groups with arthritis $(n=75)$ in physical 
training techniques (pool group, $n=13$ ) on all measures, including the Health Assessment Questionnaire and Functional score. However, $66 \%$ of all patients receiving physical training reported a general improvement in activities of daily living.

This study's findings of significant differences between groups in the Physical Component are similar to those found by Minor et al. (1989) in their study of aerobic versus nonaerobic exercise in patients with arthritis $(n=120)$. After 12 weeks, the aquatic $(n=40)$ and walking exercise groups $(n=28)$ reported significant improvements in physical activity $(p=.009)$ as compared to the ROM control group $(\mathrm{n}=28)$ on the original AIMS subscales. Unlike the current research study, in which no significant improvements were seen on the AIMS2 Affect Component measuring psychological well-being (Level of Tension and Mood), Minor et al. found significant positive changes in anxiety $(p=.004)$, and depression $(p=$ .007). However, this study's findings on the Symptom (Arthritis Pain) and Social Interaction (Social activity and Support from Family and Friends Scales) Components corresponded with Minor et al.'s, who also reported no significant changes in pain $(p=.216)$ and in social activity $(p=.572)$. The aquatics group maintained their improvements in physical activity at one year follow up, but changes in anxiety and depression were not maintained.

Several reasons may account for the small degree of change on most AIMS2 variables from pre to post-test. The measured length of time for AFAP participation (twice weekly for eight weeks) was short. "For behavioral changes to occur and then produce changes in health status often takes a longer period of time" (Burckhardt et al., 1994, p. 718). Also, the AIMS2 scales were designed to discriminate most reliably near the centers of their ranges with subjects' scores expected to fall in a normal distribution (Daltroy, 1997). Many of the scores (five scales each for both groups) did fall at the extremes of the scale, with normalized 
mean scores close to or less than 1.00 with a low standard deviation. The AIMS2 instrument may not have been sensitive enough to pick up small changes to show all improvements when mean scores fall in this extreme range.

\section{Implications for Practice}

This research has implications that could affect the clinical practice of occupational therapy. Information about the effectiveness of community based programs to which occupational therapists refer patients is vital to discharge planning. Continuation of a home exercise program after discharge from therapy is an essential long term goal established for all patients. This research supports recommending participation in AFAP water exercise to maintain or even facilitate improvements in function in older persons with arthritis. Though generalization of this study is limited due to small sample size and convenience sampling method, the findings do support regular participation in AFAP aquacize for older women with arthritis. Participation in structured group aquatic exercise was shown to be more effective in improving health status, specifically in the physical component, than other forms of exercise. The aquacize participants reported significantly more improvements in arm function and in ability to perform household tasks than the comparisons. Due to this intervention, statistically significant improvements were found in the physical component area of functioning, affecting: mobility level; walking and bending; arm, hand and finger function; self-care; and household tasks. All of these areas are within the domain of concern of occupational therapists.

Aquatic therapy currently has been gaining in popularity with physical therapists, however, occupational therapists have been slow to incorporate this modality into their practice. Only $13 \%$ of 137 respondents, out of 250 randomly selected therapists with a 
specialty in physical disabilities, utilized pool-based activities in their clinical practice (Fricke, 1995). To date, no studies have been published by occupational therapists utilizing aquatic therapy in their practice. However, the general goals established by the Arthritis Foundation in development of their program are identical to specific goals occupational therapists establish for their patients: improve strength and flexibility using structured activity, encourage participation through group involvement, promote well-being and health, and facilitate function. More research is needed to validate the application of aquatic therapy to occupational therapy clinical practice.

\section{Recommendations for Future Research}

Due to sample size limitations and convenience sampling method, the results of this study must be viewed as exploratory in nature. Further research is indicated. The following are recommendations to enhance present knowledge and research:

1. Replication of this study should be conducted on a larger sample size, allowing greater representation of the population.

2. This study should be replicated as experimental research using a random group assignment, assisting in justifying significance.

3. The comparison group of this study can regularly participate in one form of structured group community based therapeutic exercise, such as "Sit \& Be Fit", Yoga, or T'ai Chi.

4. Alternative measures to assess health status are needed to detect small changes in function. More reliability and validity testing needs to be done on shortened versions of the AIMS2.

5. More research is needed to compare community based aquacize to individual 
aquatic therapy as performed in a clinical setting by a professionally trained occupational therapist.

\section{Summary}

Arthritis is a musculoskeletal and connective tissue disorder that impacts millions of Americans; causing chronic pain, physical dysfunction, functional impairment, work disability and income loss, as well as psychosocial problems. The Centers for Disease Control and Prevention project that the prevalence of arthritis will increase to 59.4 million Americans by the year 2020 (as cited by the AF, 1996c).

The Arthritis Foundation offers numerous programs and services to assist persons to manage their arthritis and improve quality of life. The Arthritis Foundation Aquatic Program (AFAP) was developed in 1984 with a specific protocol of gentle warm water activities designed to increase participants' strength and flexibility, encourage participation in group activity, and promote well-being and health.

These goals are synchronous to occupational therapists' concerns, who seek interventions to maximize the level of physical, social, and psychological well-being of their clients in order to enhance their functional independence. Occupational therapists need to be aware of the efficacy of programs to which they refer their arthritic clients, concurrent with or upon discharge from treatment.

Health, occupation, and function are intimately linked concepts underlying the theory and practice of occupational therapy. Functional health is defined as an individual's self-reported ability to perform activities of daily living, and participate in work and leisure activities (Liang \& Jette, 1981; Meenan et al., 1992). The Constitution of the World Health Organization, adopted in 1946, globally defined health as "a state of complete 
physical, mental, and social well being and not merely the absence of disease and infirmity" (WHO, 1958, p. 459). For occupational therapists, health is conceptualized to not only be maintained through continuation of activity (Rogers, 1989), but that persons can influence the state of their health through performance of occupation (Resolution 532-79, 1979).

This researcher hypothesized that through participation in Arthritis Foundation sponsored aquacize activities, persons with arthritis can influence the state of their health. The purpose of this research was to evaluate if participation in AFAP water exercise classes would influence health status in community living older persons with various forms of arthritis. Regular inclusion of this occupation into participants' daily life was hypothesized to be therapeutic in improving self-reported functioning and health status, as measured by the twelve scales of the Arthritis Impact Measurement Scales 2 (Meenan et al., 1992). Whether AFAP participants would report more improvements in health status than a comparison group also regularly engaged in various types of therapeutic exercise was tested as well. A quasi-experimental two group pre- post test research design was employed to test the two research hypotheses.

The AIMS2 was completed twice over an eight week time span by the two homogeneous groups of women. Though generalization of this study is limited due to small sample size and convenience sampling method, the findings do support regular participation in AFAP aquacize for older women with arthritis. Participation in structured group aquatic exercise was shown to be more effective in improving health status, specifically in the physical component, than other forms of exercise. Some evidence was provided to accept the first research hypothesis: that regular participation in Arthritis Foundation sponsored aquacize classes will be effective in improving health status of older 
persons with arthritis.

Due to this intervention, statistically significant improvements were found in the physical component area of functioning, affecting: mobility level; walking and bending; arm, hand and finger function; self-care; and household tasks. All of these areas are within the domain of concern of occupational therapists. Information about the effectiveness of this community based program is relevant to occupational therapists: to assist in discharge planning and to further knowledge of a currently underutilized therapeutic modality. This research supports occupational therapists recommending participation in AFAP water exercise to maintain or even facilitate improvements in function in older persons with arthritis upon discharge from therapy.

The aquacize participants also reported significantly more improvements in arm function and in ability to perform household tasks than the comparisons. Some evidence was provided to accept the second research hypothesis: that older persons with arthritis, after regular participation in Arthritis Foundation sponsored aquacize classes, will report more improvements in health status than a comparison group also regularly engaged in various types of therapeutic exercise. The findings suggest that thru Arthritis Foundation sponsored aquacize activity, persons can influence the state of their health. 


\section{List of References}

Abdel-Moty, A. R., Maguire, G. H., Kaplan, S. H., \& Johnson, P. (1996). Stated versus observed performance levels in patients with chronic low back pain. Occupational Therapy in Health Care, 10 (1), 3-23.

Adler, A. J. (1993). Water immersion: Lessons from antiquity to modern times. Contributions to Nephrology, 102, 171-186.

American Occupational Therapy Association (1994). Uniform terminology for occupational therapy (3rd ed.). Rockville, MD: American Occupational Therapy Association.

Arthritis Foundation. (1996a). Arthritis Foundation aquatic program (AFAP). [Brochure]. Atlanta, GA: Author.

Arthritis Foundation. (1996b). Exercise and your arthritis. [Brochure]. Atlanta, GA: Author.

Arthritis Foundation. (1996c). Facts and tactics [On-line]. Available: http://www. arthritis.org/facts.

Arthritis Foundation, \& Young Mens Christian Association (1990). Arthritis foundation YMCA aquatic program (AFYAP) \& AFYAP plus: Instructor's manual. Atlanta: Arthritis Foundation \& YMCA.

Arthritis Health Professions Association (AHPA) Task Force (1986). Roles and functions of occupational therapy in the management of patients with rheumatic diseases. The American Journal of Occupational Therapy, 40 (12), 825-829.

Bacon, M.C., Nicholson, C., Binder, H., \& White, P.H. (1991). Juvenile rheumatoid arthritis: Aquatic exercise and lower-extremity function. Arthritis Care and Research, 4 (2), 102-105.

Bates, A., \& Hanson, N. (1992). Aquatic exercise therapy. Westbank, British Columbia, Canada: Swystun \& Swystun.

Berger, B. G. \& Owen, D. R. (1983). Mood alteration with swimming - Swimmers really do "feel better". Psychosomatic Medicine, 45 (5), 425-433.

Berkow, R. \& Fletcher, A. J. (Eds). (1992). Musculoskeletal and connective tissue disorders. The Merck manual of diagnosis and therapy (16th ed.) (pp. 1293-1378). Rahway, NJ: Merck \& Co.

Blalock, S. J. (1992). Introduction to special issue: Health status assessment. Arthritis Care and Research, 5 (3), 117-118. 
Bonder, B. (1994). The psychosocial meaning of activity. In B. R. Bonder \& M. B. Wagner (Eds.), Functional performance in older adults (pp.28-40). Philadelphia: F. A. Davis.

Brook, R. H., Ware, J. E., \& Davies-Avery A., Williams, K. N., Stewart, A. L., Johnston, S. A., Donald, C. A., \& Rogers, W. H. (1979). Overview of adult health status measures fielded in Rand's Health Insurance Study. Medical Care [July supplement] 17, 1131.

Burckhardt, C. S., Mannerkorpi, K., Hedenberg, L., \& Bjelle, A. (1994). A randomized, controlled clinical trial of education and physical training for women with fibromyalgia. The Journal of Rheumatology 21 (4), 714-720.

Christiansen, C. (1991). Occupational therapy: Intervention for life performance. In C. Christiansen \& C. Baum (Eds.), Occupational therapy: Overcoming human performance deficits (pp. 3-43). Thorofare, NJ: Slack.

Christiansen, C. \& Baum (Eds.) (1991). Glossary. In C. Christiansen \& C. Baum (Eds.), Occupational therapy: Overcoming human performance deficits (pp. 847-860). Thorofare, NJ: Slack.

Daltroy, L. H. (1997). Common problems in using, modifying, and reporting on classic measurement instruments. Arthritis Care and Research 10 (6), 441-447.

Danneskiold-Samsoe, B., Lyngberg, K., Risum, T., \& Telling, M. (1987). The effect of water exercise therapy given to patients with rheumatoid arthritis. Scandinavian Journal of Rehabilitation Medicine 19, 31-35.

DeVylder, S. (1995). Decreasing pain through aquatic therapy. Rehab Management $\underline{8}(6), 110-111$.

Dunn, W., Brown, C., \& McGuigan, A. (1994). The ecology of human performance: A framework for considering the effect of context. The American Journal of Occupational Therapy, 48, 595-607.

Edwards, D. F. (1994). Prevention of performance deficits. In B. R. Bonder \& M. B. Wagner (Eds.), Functional performance in older adults (pp.270-283). Philadelphia: F. A. Davis.

Fowles, D. G. (1995). A profile of older Americans: 1995. [Brochure]. Washington, DC: American Association of Retired Persons (AARP) \& Administration on Aging (AoA).

Fricke, J. E. (1995). A survey of the use of aquatic therapy among occupational therapists [CD-ROM] (Master's thesis, D'Youville College). Abstract from: ProQuest File: Masters Abstracts International Item: AAC1361545. 
Green, J.R., McKenna, F., Redfern, E.J., \& Chamberlain, M.A. (1993). Home exercises are as effective as outpatient hydrotherapy for osteoarthritis of the hip. British Journal of Rheumatology. 32, 812-815.

Hansen, T. M., Hansen, G., Langgaard, A. M., \& Rasmussen, J. O. (1993). Longterm physical training in rheumatoid arthritis. A randomized trial with different training programs and blinded observers. Scandinavian Journal of Rheumatology, 22, 107-112.

Harrison, R. A., Hillman, M., Bulstrode, S. (1992). Loading of the lower limb when walking partially immersed: Implications for clinical practice. Physiotherapy, 78, (3), 164-166.

Heyneman, C. A., \& Premo, D. E. (1992). A 'water-walkers' exercise program for the elderly. Public Health Reports, 107 (2), 213-217.

Hittle, J. M., Pedretti, L. W., \& Kasch, M. C. (1996). Rheumatoid Arthritis. In L. W. Pedretti (Ed.), Occupational therapy: Practice skills for physical dysfunction (4th ed.) (pp. 639-660). St. Louis,MO: Mosby.

Hochberg, M. C., Chang, R. W., Dwosh, I., Lindsey, S., Pincus, T., Wolfe, F. (1991). The American College of Rheumatology 1991 revised criteria for the classification of global functional status in rheumatoid arthritis. Arthritis and Rheumatism, 35, 498-502.

Huey, L., \& Forster, R. (1993). The complete waterpower workout book: Programs for fitness, injury prevention, and healing. NY: Random House.

Jette, A. M. (1980). Health status indicators: Their utility in chronic-disease evaluation research. Journal of Chronic Diseases, 33, 567-579.

Jette, D. U., \& Downing, J. (1994). Health status of individuals entering a cardiac rehabilitation program as measured by the medical outcomes study 36 -item short-form survey (SF-36). Physical Therapy, 74 (6), 521-527.

Johnson, C. R. (1988). Aquatic therapy for an ALS patient. American Journal of Occupational Therapy 42, (2), 115-120.

Kielhofner, G. (1983). Health through occupation: Theory and practice in occupational therapy. Philadelphia, F. A. Davis.

Last, J. M. (1987). Public health and human ecology. East Norwalk, CT: Appleton \& Lange.

Liang, M. H., \& Jette, A. M. (1981). Measuring functional ability in chronic arthritis. Arthritis and Rheumatism, 24 (1), 80-86. 
Lindsley, C. B. (1996). Juvenile rheumatoid arthritis. In R. E. Rakel (Ed.), Conn's current therapy: Latest approved methods of treatment for the practicing physician (pp. 944955). Philadelphia: W. B. Saunders.

Mason, J. H., Anderson, J. J., \& Meenan, R. F. (1988). A model of health status for rheumatoid arthritis: A factor analysis of the AIMS. Arthritis and Rheumatism, 37, 714-720.

Mason, J. H., Anderson, J. J., \& Meenan, R. F. (1989). Applicability of a health status model to osteoarthritis. Arthritis Care and Research, 2 (3), 89-93.

Mason, J. H., Weener, J. L., Gertman, P. M., \& Meenan, R. F. (1983). Health status in chronic disease: A comparative study of rheumatoid arthritis. Journal of Rheumatology, 10, (5), 785-788.

McDowell, I. \& Newell, C. (1987). Measuring health: A guide to rating scales and questionnaires. NY: Oxford University Press.

McGinnis, G. E., Seward, M. L., DeJong, G., Osberg, J. S. (1986). Program evaluation of physical medicine and rehabilitation departments using self-report Barthel. Archives of Physical Medicine and Rehabilitation, 67, 123-125.

Meenan, R. F. (1982). The AIMS approach to health status measurement: Conceptual background and measurement properties. The Journal of Rheumatology. 9 (5), 785-788.

Meenan, R. F., Anderson, J. J., Kazis, L. E., Egger, M. J., Altz-Smith, M., Samuelson, C. O., Willkens, R. F., Solsky, M. A., Hayes, S. P., Blocka, K. L., Weinstein, A., Guttadauria, M., Kaplan, S. B., \& Klippel, J. (1984). Outcome assessment in clinical trials: Evidence for the sensitivity of a health status measure. Arthritis and Rheumatism, 27 (12), 1344-1352.

Meenan, R. F., Gertman, P. M., Mason, J. H. (1980). Measuring health status in arthritis: The Arthritis Impact Measurement Scales. Arthritis and Rheumatism, 23 (2), $146-$ 152.

Meenan, R. F., Gertman, P. M., Mason, J. H., Dunaif, R. (1982). The Arthritis Impact Measurement Scales: Further investigations of a health status measure. Arthritis and Rheumatism, 25 (9), 1048-1053.

Meenan, R. F. \& Mason, J. H. (1994). AIMS2 User's Guide. Boston, MA: Boston University Arthritis Center.

Meenan, R. F., Mason, J. H., Anderson, J. J., Guccione, A. A., \& Kazis, L. E. (1992). AIMS2: The content and properties of a revised and expanded arthritis impact measurement scales health status questionnaire. Arthritis and Rheumatism, 35 (1), 1-10. 
Melvin, J. L. (1989). Roles and functions of occupational therapy in the management of patients with rheumatic diseases. In Rheumatic disease in the adult and child: Occupational therapy and rehabilitation (3rd ed.). Philadelphia: F. A. Davis.

Meyer, C. L., \& Hawley, D. J. (1994). Characteristics of participants in water exercise programs compared to patients seen in a rheumatic disease clinic. Arthritis Care and Research, 7 (2), 85-89.

Minor, M. A., Hewett, J. E., Webel, R. R., Anderson, S. K., \& Kay, D. R. (1989). Efficacy of physical conditioning exercise in patients with rheumatoid arthritis and osteoarthritis. Arthritis and Rheumatism, 32 (11), 1396-1405.

Moor, F. B., Peterson, S. C., Manwell, E. M., Noble, M. C., \& Muench, G. (1964). Manual of hydrotherapy and massage. Boise, ID: Pacific Press.

Nelson, D. L., \& Peterson, C. Q. (1989). Enhancing therapeutic exercise through purposeful activity: A theoretic analysis. Topics in Geriatric Rehabilitation, 4 (4), 12-22.

Olsen, P. J. (1995). Aquatic physical therapy for chronic painful conditions: An outcome study. Aquatic Physical Therapy Report, 3, (3), 12-14.

Patrick, D. L., Bush, J. W., \& Chen, M. M. (1973). Toward an operational definition of health. Journal of Health \& Social Behavior, 14, 6-23.

Pedretti, L. W., \& Wade, I. E. (1996). Therapeutic modalities. In L. W. Pedretti (Ed.), Occupational therapy: Practice skills for physical dysfunction (4th ed.) (pp. 293-317). St. Louis,MO: Mosby.

Pelletier, K. R. (1979). Holistic medicine: From stress to optimum health. NY: Delacorte Press.

Potts, M. K., \& Brandt, K. D. (1987). Evidence of the validity of the Arthritis Impact Measurement Scales. Arthritis and Rheumatism, 30 (1), 93-96.

Rasmussen, J.O., \& Hansen, T.M. (1989). Physical training for patients with ankylosing spondylitis. Arthritis Care and Research.2 (1), 25-27.

Reed, K. L. \& Sanderson, S. N. (1992). Concepts of occupational therapy (3rd ed.). Baltimore: Williams \& Wilkins.

Reister, V. C., \& Cole, A. J. (1993). Start active, stay active in the water. The Journal of Physical Education. Recreation \& Dance, 64, 52-54.

Resolution 532-79 (1979). Occupation as the common core of occupational therapy: Representative Assembly minutes. April 1979, Detroit, Michigan. The American Journal of Occupational Therapy, 33, 785. 
Reynolds, J. P. (1995). What is the "outcomes movement": What does it mean to PTs?. PT Magazine of Physical Therapy, 3 (7), 49-52, 67-68.

Rogers, J. C. (1989). Therapeutic activity and health status. Topics in Geriatric Rehabilitation, 4 (4), 1-11.

Semble, E. L. (1995). Treatment of rheumatoid arthritis. Archives of Physical Medicine and Rehabilitation 76, 190-201.

Smit, T. E., \& Harrison, R. (1991). Hydrotherapy and chronic lower back pain: A pilot study. The Australian Journal of Physiotherapy, 37, 229-234.

Steinbrocker, O., Traeger, C. H., \& Batterman, R. C. (1949). Therapeutic criteria in rheumatoid arthritis. The Journal of the American Medical Association, 140 (8), 659-662.

Stenstrom, C.H., Lindell, B., Swanberg, E., Swanberg, P., Harms-Ringdahl, K., Nordemar, R. (1991). Intensive dynamic training in water for rheumatoid arthritis functional class $I I$ - a long-term study of effects. Scandinavian Journal of Rheumatology, 20, 358-365.

Swezey, R. L. (1993). Rehabilitation medicine \& arthritis. In McCarty, D. J., \& Koopman, W. J. (Eds.) Arthritis \& allied conditions: a textbook of rheumatology (12th ed.) (pp. 888-893). Philadelphia: Lea \& Febiger.

Thomas, C. L. (Ed.). (1993). Taber's cyclopedic medical dictionary (17th ed.). Philadelphia: F. A. Davis.

Thomson, G. T., Steinfield, S. M., \& Gall, R. M. (1996). Ankylosing spondylitis. In R. E. Rakel (Ed.), Conn's current therapy: Latest approved methods of treatment for the practicing physician (pp. 945-948). Philadelphia: W. B. Saunders.

Tork, S.C., \& Douglas, V. (1989). Arthritis water exercise program evaluation: a Self- assessment survey. Arthritis Care and Research. 2 (1), 28-30.

Trombly, C. A. (1989). Occupational therapy for physical dysfunction (3rd ed.). Baltimore: Williams and Wilkins.

Tsukahara, N., Toda, A., Goto, J., \& Ezawa, I. (1994). Cross-sectional and longitudinal studies on the effect of water exercise in controlling bone loss in Japanese postmenopausal women. Journal of Nutritional Science and Vitaminology, 40, 37-47.

Weaver, (1996). Osteoarthritis. In R. E. Rakel (Ed.), Conn's current therapy: Latest approved methods of treatment for the practicing physician (pp. 954-956). Philadelphia: W. B. Saunders.

Weinstein, L. B. (1986). The benefits of aquatic activity. Journal of Gerontological Nursing, 12, (2), 6-11. 
Weiss, C. R. \& Jamieson, N. B. (1987). Affective aspects of an age-integrated water exercise program. The Gerontologist, 27 (4), 430-433.

Weiss, C. R. \& Jamieson, N. B. (1989). Women, subjective depression, and water exercise. Health Care for Women International, 10, 75-87.

West, W. L. (1984). A reaffirmed philosophy and practice of occupational therapy for the 1980s. The American Journal of Occupational Therapy, 38 (1), 15-23.

World Health Organization (1958). The first ten years of the World Health Organization. Geneva: World Health Organization. 
APPENDICES 
APPENDIX A

EXERCISE QUESTIONNAIRE 
Month Day Year

Please begin by providing the following information about yourself. These answers are not part of the study but simply serve to help determine if you meet the criteria I am studying.

\begin{tabular}{|l|l|l|}
\hline $\begin{array}{l}\text { 1. Have you been told by your physician that you have some form } \\
\text { of arthritis? }\end{array}$ & YES & NO \\
\hline $\begin{array}{l}\text { 2. Have you been told by your physician that you must NOT } \\
\text { exercise? }\end{array}$ & YES & NO \\
\hline $\begin{array}{l}\text { 3. Do you regularly participate in an ongoing exercise routine? } \\
\text { (for example: walking, swimming, water exercise, bicycling, } \\
\text { aerobic exercise, dancing, running, jogging, etc.) }\end{array}$ & YES & NO \\
\hline $\begin{array}{l}\text { A) If yes: on the average, what is the total number of hours you exercise } \\
\text { in a week? }\end{array}$ \\
$\begin{array}{l}\text { B) If yes: what types of exercise do you do? Please list: } \\
\text { Have you ever participated in any type of water exercise class? }\end{array}$ & YES & NO \\
\hline $\begin{array}{l}\text { 4. Have you ever participated in Arthritis Foundation water } \\
\text { exercise classes? }\end{array}$ & YES & NO \\
\hline
\end{tabular}

A) If yes: how long ago did you last attend these aquacize classes? Month/Year

B) If yes: how frequently did you attend aquacize classes?

(Please Circle Only One Answer)

1=Always $\quad \mathbf{2}$ =Very Often $\quad 3$ =Sometimes $\quad \mathbf{4}$ =Almost Never

C) If yes please estimate the total length of time you have participated in Arthritis Foundation water exercise classes (exclude breaks of time due to discontinuation of classes, vacation, or illness).

(Please Circle Only One Answer)

1=0-3 Months 2=3-6 Months 3=6 Months-1 Year 4=1-2 Years 5=2-3 Years $\quad 6=3-5$ Years $\quad 7=$ Greater than 5 Years

Thank you for your participation. If you are uncertain about any of these questions, please feel free to ask the principal investigator for clarification: Rose Ann Curboy, at (561) 744-2822. 


\begin{abstract}
APPENDIX B
PERMISSION TO USE
\end{abstract}

ARTHRITIS IMPACT MEASUREMENT SCALES (AIMS2) 
February 15, 1997

Dr. Rober F. Meenan

Director

Boston Lniversity School of Public Health

So East Concord Street

Boston, MA 02118-2394

RE: AIMS2 Permission Request

Dr. Meenan:

I am an occupational therapy graduate student at Florida International University, Miami in the process of formulating my master's thesis. I am interested in utilizing the revised Arthritis Impact . Weasurement Scale (AIMS2) to assess the effects of the Arthritis Foundation sponsored water exercise program on local participants' health status. I believe that the AIMSZ is the most appropriate instrument for my research.

If vou grant permission, please sign this form in the space provided and return it to me, or otherwise indicate. I appreciate your expediting this information because I hope to begin coliecting baseline data on April 1, 1997 when a new session commences.

Please inform me regarding the necessary procedure to obtain the AlMS2 User's Guide. Thank you in advance for your authorization and for your assistance.

Sincerely,

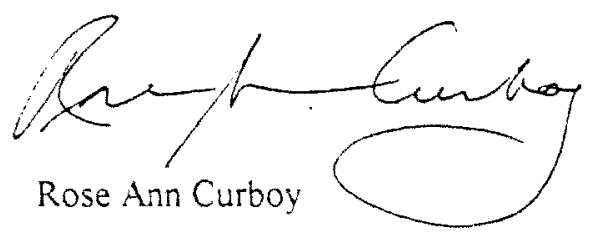

Permission is hereby granted:

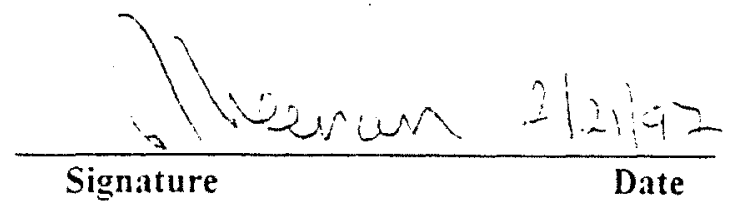


APPENDIX C

LETTER FROM AIMS2 AUTHOR 


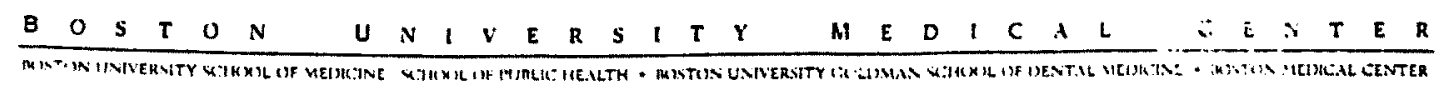

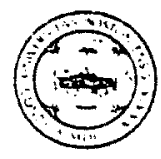

Boston University

Office of the Dean

School of

Public Health

su tust Cuncord itrit:

Buntun. Massuthuserts

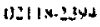

TEL: $61^{-}-3 \times, .0 \%+21$

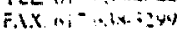

January 1997

Dear Colleague:

Thank you for your request for information on the second version of the Arthritis Impact Measurement scales. (AIMS2). A copy of the new instrument is enclosed along with a brief User's Guide that describes scoring.

To summarize, three types of changes have been made in this new version of AIMS. First, modifications have been made in the original nine scales. Some items with low reliability and/or sensitivity were eliminated so that all scales now have four or five items. Three items were removed from the household physical activities scale because they dealt with cognitive functions rather than physical functions. The number of response options per item was also standardized, eliminating all yes/no responses.

Second, we have included three new scales: arm function, work and social support. These three scales were added to assess aspects of health status that were not covered in the original AIMS. Work information can be used as a categorical variable lemployed, student. disabled, etc.) or as a four item scale. Finally, three new pages were added to AIMS2 to assess satisfaction, problem attribution, and problem prioritization.

The measurement properties of AIMS2 have proven to be very similar to those of the original instrument. We therefore do not feel that AIMS2 needs to be re-tested for reliability or validity in all those groups or settings where the original AIMS has already been tested.

The AIMS2 is a copyrighted instrument. Investigators who plan to use it in commercially sponsored research should contact me for permission and to discuss a possible user's fee. Academic users have authorization to employ the AIMS2 without restriction.

Best of luck with your research.

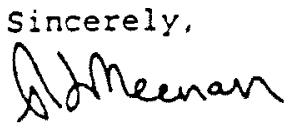

Robert $F$. Meenan, MD, MPH, MSA

RFM:der Dean 


\section{APPENDIX D}

INFORMED CONSENT FORM 


\section{Informed Consent}

I freely and voluntarily consent to be a participant in the research project entitled "The Effects of Participation in an Arthritis Foundation Sponsored Aquacize Program on Health Status" to be conducted during the spring, 1997, with Rose Ann Curboy as Principal Investigator.

I understand the purpose of this research is to determine the effects of exercise on health

I understand that the research procedures will be as follows: I will complete a self-report health status questionnaire, the Arthritis Impact Measurement Scales (AIMS2), when I first begin the Arthritis Foundation sponsored water exercise program. Aquacize classes will meet on Tuesday and Thursday momings for one hour each week. I agree to regularly attend these classes for at least 45 minutes of that hour for at least 12 of 16 consecutive sessions (eight weeks of classes). The certified water exercise instructor, Kathy Andio, will record my attendance during this time. I will complete the health status questionnaire again at conclusion of the 8 weeks.

I understand that there are no known risks or benefits involved in my participation in this experiment. I understand that I am one of 40 people in this research project. I have been told that the Arthritis Impact Measurement Scales (AIMS2) will be kept strictly confidential. All measurements will be identified only by a code number, and all information will be described as group data. My individual measurements will not be revealed to anyone without my express permission.

I understand that I may withdraw my consent and discontinue participation in this research project at any time with no negative consequences. I have been given the right to ask questions concerning the procedure, and any questions have been answered to my satisfaction.

I understand that if I desire further information about this research I should contact Rose Ann Curboy at (561) 744-2822 or Dr. Susan Kaplan, the faculty advisor of the Principal Investigator, at Florida International University, Occupational Therapy Department at (305) 3483105. I have been offered a copy of this informed consent form.

I have read and I understand the above.

Participant's Signature

Date

I have explained and defined in detail the research procedure in which the participant has agreed to participate, and have offered him/her a copy of this informed consent form. 
APPENDIX E

AQUATIC COMPLEX HONORED 


\section{Aquatic Complex honored}

JUPITER - The North County Aquatic Complex Water Fitness Program was named the ninth out of 100 fitness programs in the country by the U.S. Water Fitness Association, based in Boynton Beach, said Sally Welsh-Franke, swimming pool manager at the local Aquatic Complex.

In addition, the Jupiter program also was given awards as the top Water Fitness Program for both the county and state, she said.

Welsh-Franke made the announcements at a reception, Thursday, at the complex while presenting one of the instructors with a plaque.

Kathy Andio, an exercise instructor at the Jupiter pool, was honored as the county Parks and Recreation Department's Outstanding Water Exercise Instructor of the Year. 